\title{
General Volume Sizing Strategy for Thermal Storage System using Phase Change Material for Concentrated Solar Thermal Power Plant
}

\author{
Ben $\mathrm{Xu}^{1}$, Peiwen $\mathrm{Li}^{1} *$, Cholik Chan ${ }^{1}$, Eric Tumilowicz ${ }^{2}$ \\ 1. Department of Aerospace and Mechanical Engineering \\ The University of Arizona, Tucson, AZ 85721, USA \\ 2. Sandia National Laboratories, Albuquerque, NM 87185-0614, USA \\ *Corresponding author. Tel.: 520-626-7789; Fax: 520-621-8191; \\ Email address: peiwen@email.arizona.edu (Peiwen Li)
}

\begin{abstract}
With an auxiliary large capacity thermal storage using phase change material (PCM), Concentrated Solar Power (CSP) is a promising technology for high efficiency solar energy utilization. In a thermal storage system, a dual-media thermal storage tank is typically adopted in industry for the purpose of reducing the use of the heat transfer fluid (HTF) which is usually expensive. While the sensible heat storage system (SHSS) has been well studied, a dual-media latent heat storage system (LHSS) still needs more attention and study. The volume sizing of the thermal storage tank, considering daily cyclic operations, is of particular significance. In this paper, a general volume sizing strategy for LHSS is proposed, based on an enthalpy-based 1D transient model. One example was presented to demonstrate how to apply this strategy to obtain an actual storage tank volume. With this volume, a LHSS can supply heat to a thermal power plant with the HTF at temperatures above a cutoff point during a desired 6 hours of operation. This general volume sizing strategy is believed to be of particular interest for the solar thermal power industry.
\end{abstract}

Key Words: Concentrated Solar Power (CSP), Latent Heat Storage System (LHSS), Phase Change Material (PCM), General Volume Sizing Strategy, Enthalpy-based 1D Transient Model

\section{Introduction}

During the past few years, concentrated solar power (CSP) generation is becoming attractive because of its ability to store excessive energy and extend the daily operation of a CSP plant during periods of intermittent sunlight and nights. It also can smooth out the short-term transients such as the mismatch between energy supply and demand by providing load leveling [1]. A CSP plant uses solar tower, parabolic troughs, or linear Fresnel reflectors to concentrate sunlight and produce intense heat for Heat Transfer Fluid (HTF) which carries heat for thermal energy storage as well as for thermal cycles in conventional power plants [2]. A key requirement to make this energy option competitive, however, is the use of a thermal energy storage system which is filled with energy storage materials [3]. 
With respect to the storage material, the thermal energy storage tank can be operated on sensible heat, latent heat, or a combination of both. Since the latent heat or combined latent/sensible heat storage system can offer a larger thermal storage capacity and a significant reduction of storage tank volume compared to the use of sensible heat alone [4, 5], a CSP plant using PCM latent heat storage system (LHSS) is promising for large scale solar thermal energy application. During the past few years, LHSS has been getting a lot of attention [6]. A major technology barrier limiting the use of PCM, however, is the higher thermal resistance provided by its intrinsically low thermal conductivity. As a result, it requires a large heat transfer surface area of interaction between HTF and PCM. One promising approach is to incorporate the PCM in small capsules [7]. For example, PCM stored in capsules with a diameter of $10 \mathrm{~mm}$ offers a surface area of more than 300 square meters per cubic meter [8]. Because of this motivation, research to find suitable materials and processes to encapsulate high temperature PCM mixtures is underway $[9,10]$. In the current work, encapsulated PCM would be used as filler material in contact with HTF in the thermal storage tank.

A dual-media or a solid-packed thermal storage system is believed to significantly reduce the amount of HTF in the system, compared to the two-tank direct storage system [11]. It will, however, more or less sacrifice the energy storage efficiency due to the heat transfer between the HTF and solid filler material [12]. During the heat charge process, hot HTF flows downward through the storage tank from the top and gives thermal energy to the storage material, while during a discharge process, cold HTF flows into the tank from the bottom, and flows out with a high temperature from the top after obtaining heat. The process is shown in Fig. 1.

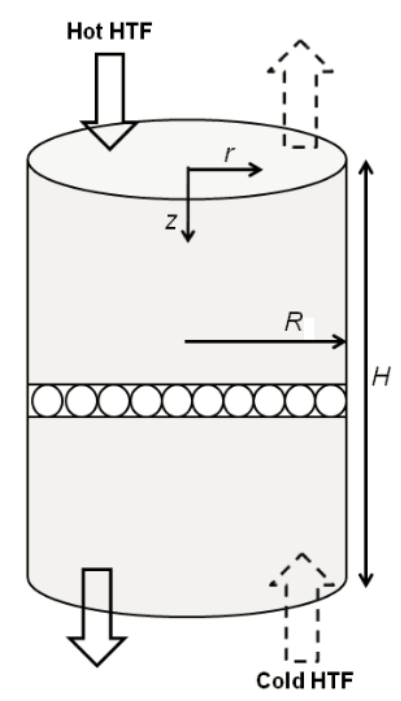

Fig. 1. Schematic of thermal energy storage tank with encapsulated PCM

Buoyancy force ensures stable thermal stratification of hot and cold fluids within the single storage tank which is also called a thermocline storage tank [13]. The charge process takes place during the day when solar energy is available, while discharge occurs whenever the sun is not available or when there is a peak demand in electricity. The sequence of a single charge process followed by a discharge process is referred to as one cycle, and a cyclic periodic steady state will finally be reached after several repeated cycles. Then the temperature distribution of filler 
material and HTF will be independent of the most-initial condition in the tank [14]. Li et al. [15] has performed numerical simulations to verify the existence of cyclic periodic steady state. In this paper, all computations are processed to repeat charge/discharge cycles, and cyclic periodic steady state solutions were obtained as the results.

During the past two years, researchers have done a lot of work to explore the sensible thermocline storage system. Li et al. $[16,17]$ provided a generalized chart for the design and calibration of thermocline sensible heat storage system. Wu et al. [18] investigated the impact of concrete structure on the thermal performance of the dualmedia thermocline thermal storage tank using concrete as the solid medium. Prasad et al. [19] numerically studied the transient behavior and thermal storage capability of a sensible heat storage unit with embedded charging tubes by employing three storage materials, namely, concrete, cast steel, and cast iron. Xu et al. [20] presented a comprehensive transient, two-dimensional, two-phase model for heat transfer and fluid dynamics within the packedbed thermocline sensible storage system. Yang et al. [21] developed a comprehensive, two-temperature model to investigate the cyclic operations of a thermocline with a commercially available molten salt as the heat transfer fluid and quartzite rocks as the filler.

Relatively few works on the performance of LHSS are found in the literature. Nevertheless, there are still some papers presented numerical modeling of LHSS. A model by Felix Regin and Solanki [22] considered a simple charge process of a tank with PCM filler for a parametric study of material properties. Following that, a model by Wu et al. [23] applied an implicit finite difference method to solve the equations for the case with the presence of PCM filler in the tank to consider general scenarios. Results from that model, however, featured numerous oddities and oscillations in temperature distribution profiles. To overcome the lower thermal conductivity of PCM material, Nithyanandam and Pitchumani $[24,25]$ introduced heat transfer augmentation using thermosyphons or heat pipe. Different configurations were investigated by using CFD, and optimal orientation and design parameters were obtained. Archibold et al. [26] focused their attention on the fluid flow and heat transfer of the PCM within the spherical encapsulate. Recirculating vortexes were found in the upper region and therefore more intense melting occurs in this region. On the other hand, Vyshak and Jilani [27] used a modified enthalpy method to investigate the melting times for rectangular, cylindrical, and cylindrical shell storage configurations, and they found that melting time for cylindrical shell storage was the lowest. They also investigated the effects of inlet temperature of the heat transfer fluid. Nevertheless, to the authors' knowledge a comprehensive and accurate model for LHSS subjected to constraints dictated by the power plant operation has yet to be conceived. Nithyanandam et al. [28] presented a transient, numerical analysis of a molten salt, single tank latent thermocline energy storage system (LTES) for repeated charging and discharging cycles to investigate its dynamic response. Parametric studies have been conducted to provide guidelines for designing a packed bed PCM based storage system for CSP plant. However, their model is a 2D transient model by considering the axial heat conduction inside the encapsulated PCM, which will sacrifice the computation efficiency.

An accurate and efficient model of thermocline operation to encapsulated PCM has been proposed by Tumilowicz et al. [29, 30], called as an enthalpy-based 1D transient model. The model was developed following the work of Van Lew et al. [31] with a much needed expansion of the analysis to include encapsulated PCM fillers, and the thermal resistance inside the encapsulated PCM is also taken into account by incorporating the effective heat 
transfer coefficient, based on the work of Xu et al. [32]. The use of enthalpy-based version of Schumann's equation [33] in their model can accurately describe the heat transfer and energy storage/extraction between HTF and the packed-bed solid filler material and allow tracking of interfaces throughout the thermocline processes, which is especially necessary in the latent region where the temperature of the PCM filler remains as a constant.

For a CSP plant to be cost-competitive against other sources of energy generation on the grid without subsidy, the U.S. Department of Energy's Sun Shot Initiative calls for a storage capital cost less than $\$ 15 / \mathrm{kWh}$ for a minimum discharge period of 6 hours [34]. To achieve these targets, a CSP plant incorporated with a thermal storage system is expected to be operated with higher storage efficiency and more power output under optimized conditions. In this work, a minimum discharge period of 6 hours will be considered, and a rudimentary cost analysis will be included at the end of this paper to show the advantage of a LHSS compared to a SHSS. It is important to note that the main focus of this paper is not to provide cost analysis to thermocline storage system but a method of volume sizing. Therefore, the methodology of cost analysis and reduction in conjunction to energy storage system analysis is yet to be developed in the future.

Two charge/discharge operating strategies can significantly affect the energy storage efficiency and energy output, which include: 1) starting daily cyclic charge/discharge operation with an initially cold tank; and 2) the thermal storage system is fully charged initially before the cyclic discharge/charge operation of the power plant. In their computational results, $\mathrm{Xu}$ et al. [35] concluded that under the same operational conditions of flow rate and temperatures, SHSS is recommended to be operated under cold start, while hot start is more appropriate for LHSS since it can supply more energy output than SHSS. Thus, hot start will be adopted in this paper.

The calculations in Ref. [35] were only based on a trial storage tank volume, the HTF temperature at the exit of storage tank (herein called as output HTF temperature) cannot be maintained above a cutoff temperature during the entire time period of discharge. Below the cutoff temperature, HTF will not able to be used in the power cycle for power generation. In the current analysis for a CSP plant the cutoff temperature is set as $360{ }^{\circ} \mathrm{C}$. The volume sizing for an actual storage tank should render it to provide HTF above the cutoff temperature during the desired time period of discharge, which is of significance in improving energy storage efficiency and total extracted energy. A general volume sizing strategy for LHSS has been proposed according to the enthalpy-based 1D transient model. One example was presented to demonstrate the process of applying this strategy to obtain the storage volume, with which LHSS can supply HTF to the thermal power system with temperatures above the cutoff point during the entire 6 hours of discharge. Finally, by applying the same volume sizing strategy, a sensible heat storage system (SHSS)

using granite rocks as storage material was analyzed, and the storage tank height of SHSS has been compared with LHSS to show that the volume can be reduced significantly by adopting PCM. The general volume sizing strategy is believed to be of particular interest in the solar engineering community. It provides sizing or design guidelines for concentrated solar thermal storage engineering.

\section{Mathematical Methodology of Enthalpy-based 1D Transient Model and A Generalized Approach to Determine the Storage Volume}




\subsection{Governing equations}

The governing equations to describe the heat transfer between HTF and filler material [30] are as follows:

$$
\begin{gathered}
\frac{\partial T_{f}}{\partial t}+U \frac{\partial T_{f}}{\partial z}=\frac{h S_{r}}{\rho_{f} C_{f} \varepsilon \pi R^{2}}\left(T_{r}-T_{f}\right) \\
\frac{d \bar{h}_{r}}{d t}=-\frac{h S_{r}}{\rho_{r}(1-\varepsilon) \pi R^{2}}\left(T_{r}-T_{f}\right)
\end{gathered}
$$

where $T_{f}$ denotes the fluid temperature, $T_{r}$ denotes the filler material temperature, $\bar{h}_{r}$ is the enthalpy of solid filler material, $h$ is the heat transfer coefficient between solid filler material and HTF, $\rho_{f}$ and $C_{f}$ are the density and specific heat of HTF respectively, $\rho_{r}$ is the density of filler material, $R$ is the radius of the storage tank, $U$ is the velocity of HTF passing the porous region.

The equivalent void fraction $\mathcal{E}$ shown in Eq. (1) and (2) is defined as:

$$
\varepsilon=V_{f} / V_{\text {tank }}
$$

where $V_{\text {tank }}$ is the volume of storage tank, and $V_{f}$ is the volume of HTF within storage tank.

Also, the filler capsules are assumed to have point contact, thus for convective heat transfer analysis, the surface area per unit length, $S_{r}$, as used in Eq. (1) and (2), is defined as [36]:

$$
S_{r}=f_{s}(1-\varepsilon) \pi R^{2} / r
$$

where $r$ is the radius of encapsulated filler material, $f_{s}$ is the surface shape factor, which varies depending on the particle packing scheme. For encapsulated spherical particles, $f_{s}$ is equal to 3.0.

Based on the Colburn factor relation [37], the heat transfer coefficient characterizing the convective interaction between the primary thermal storage material (porous media) and HTF can be found from reference [38]:

$$
h=0.191 \dot{m} \operatorname{Re}^{-0.278} C_{f} \operatorname{Pr}_{f}^{-2 / 3} /\left(\varepsilon \pi R^{2}\right)
$$

where $\operatorname{Re}=2 r \cdot \dot{m} /(1-\varepsilon) \rho_{f} \nu_{f} \pi R^{2}, \operatorname{Pr}_{f}=v_{f} \rho_{f} C_{f} / k_{f}$, and $\dot{m}$ is the mass flow rate.

For this enthalpy-based 1-D model, a lumped capacitance assumption is required which allows any internal temperature gradients presenting in the encapsulated filler to be encompassed in its intrinsic convection coefficient $h$. However, if the characteristic length scale of the encapsulated filler material is large, the internal thermal resistance becomes significant, and a correction to the lumped capacitance method is inevitable. Xu et al. [32] conducted a very important extension of this method for a large Biot number, and the intrinsic heat transfer $h$ in Eq. (1) and (2) can be replaced by an effective heat transfer coefficient $h_{\text {eff }}$.

The expressions of Eq. (1) and (2) still retain a filler temperature term, for which an equation of state is applied to relate it to enthalpy. 


$$
T_{r}= \begin{cases}\frac{\bar{h}_{r}-\bar{h}_{r_{-} o}}{C_{r_{-} s}}+T_{r_{-} o} & \bar{h}_{r}<\bar{h}_{r_{-} \text {melt }} \\ T_{r_{-} m e l t} & \bar{h}_{r_{-} \text {melt }} \leq \bar{h}_{r} \leq \bar{h}_{r_{-} \text {melt }}+L \\ \frac{\bar{h}_{r}-\left(\bar{h}_{r_{-} m e l t}+L\right)}{C_{r_{-} l}}+T_{r_{-} \text {melt }} & \bar{h}_{r_{-} \text {melt }}+L<\bar{h}_{r}\end{cases}
$$

where $T_{r_{-} \text {melt }}$ is the melting temperature of PCM, $L$ is the heat of fusion, and $\bar{h}_{r_{-} \text {melt }}$ is the enthalpy of PCM at the melting temperature when PCM starts to melt.

Introduce the following dimensionless variables: $\theta_{f}=\left(T_{f}-T_{L}\right) /\left(T_{H}-T_{L}\right)$, $\theta_{r}=\left(T_{r}-T_{L}\right) /\left(T_{H}-T_{L}\right) z^{*}=z / H, t^{*}=t /(H / U)$, and $\eta_{r}=\left(\bar{h}_{r}-\bar{h}_{r_{-} \text {ref }}\right) / C_{r_{-} s}\left(T_{r_{-} \text {melt }}-T_{L}\right)$, the governing equations and the equation of state in dimensionless forms are as follows:

$$
\begin{gathered}
\frac{\partial \theta_{f}}{\partial t^{*}}+\frac{\partial \theta_{f}}{\partial z^{*}}=\frac{1}{\tau_{r}}\left(\theta_{r}-\theta_{f}\right) \\
\frac{d \eta_{r}}{d t^{*}}=-\frac{H_{C R}}{\tau_{r} \theta_{r_{-} \text {melt }}}\left(\theta_{r}-\theta_{f}\right)
\end{gathered}
$$

where $\tau_{r}=\frac{U}{H} \frac{\rho_{f} C_{f} \varepsilon \pi R^{2}}{h_{e f f} S_{\text {filler }}}$, and $H_{C R}=\frac{\rho_{f} C_{f} \varepsilon}{\rho_{r} C_{r_{-} s}(1-\varepsilon)}$.

The dimensionless form of the equation of state is:

$$
\theta_{r}= \begin{cases}\eta_{r} \cdot \theta_{r_{-} m e l t}+\theta_{r_{-} r e f} & \eta_{r}<\eta_{r_{-} m e l t} \\ \theta_{r_{-} \text {melt }} & \eta_{r_{-} \text {melt }} \leq \eta_{r} \leq \eta_{r_{-} m e l t}+\frac{1}{S t f} \\ \left(\eta_{r}-\left(\eta_{r_{-} m e l t}+\frac{1}{S t f}\right)\right)\left(\frac{C_{r_{-} s}}{C_{r_{-} l}}\right) \theta_{r_{-} \text {melt }}+\theta_{r_{-} m e l t} & \eta_{r_{-} m e l t}+\frac{1}{S t f}<\eta_{r}\end{cases}
$$

where $S t f=C_{r_{-} s}\left(T_{r_{-} m e l t}-T_{L}\right) / L$.

To solve the above governing equations, the method of characteristics is applied. Details of the numerical approach for the solution of the enthalpy-based 1D transient model for LHSS are given in Tumilowicz et al. [29, 30]. For sensible thermal storage with solid spherical fillers, the enthalpy-based 1D transient model with effective heat transfer coefficient has been applied and validated by Valmiki et al. [39] with experimental data. For other 
solid-fluid structural combinations, $\mathrm{Li}$ et al. [15] conducted a comprehensive CFD-based analysis to verify the 1D transient model.

Yang and Garimella demonstrated a transient 3D model using Fluent 6.1 in 2010 [40]. Bayón and Rojas presented a 1D transient model in 2013 [41], considering the solid filler material and HTF as a single effective storage medium inside a thermocline tank. Compared to these models, the current enthalpy-based 1D transient model can precisely track the interface movement in PCM, while other models cannot because temperature is a constant at the melting interface. In addition, the thermal resistance inside the filler particles was completely neglected in other models, while the current model uses effective heat transfer coefficient to accurately include the internal thermal resistance and still keep using the lumped capacitance method for the heat conduction inside fillers. As a consequence, the current model maintains high accuracy and needs much less load of computation.

\subsection{Model validation}

Comparison of the current simulation results to experimental data by Nallusamy et al. [42] was made to demonstrate the validity of the numerical scheme of 1D model. In the experimental work, they used encapsulated spherical capsules of paraffin with melting temperature at $60{ }^{\circ} \mathrm{C}$ as the PCM, and the HTF is water. The inlet fluid temperature was maintained at $70{ }^{\circ} \mathrm{C}$ and the mass flow rate was fixed at $2 \mathrm{~L} / \mathrm{min}$. Using their experimental conditions and properties, the important parameters were estimated as:

$$
\begin{aligned}
& H_{C R}=1.008 \\
& \tau_{r}=1.0269 \\
& \theta_{f_{-i n l e t}}=1.0 \\
& \theta_{r_{O}}=\theta_{f_{O}}=0 \\
& \theta_{r_{-} \text {melt }}=0.7368 \\
& \Delta t^{*}=\Delta z^{*}=0.001
\end{aligned}
$$

Figures 2 and 3 respectively show the temperatures of the fluid and the PCM at the middle of the tank as a function of time during a heat charging process. The results from simulation and experimental tests are in a satisfactory agreement, which validates the correctness of the modeling and the computer code. 


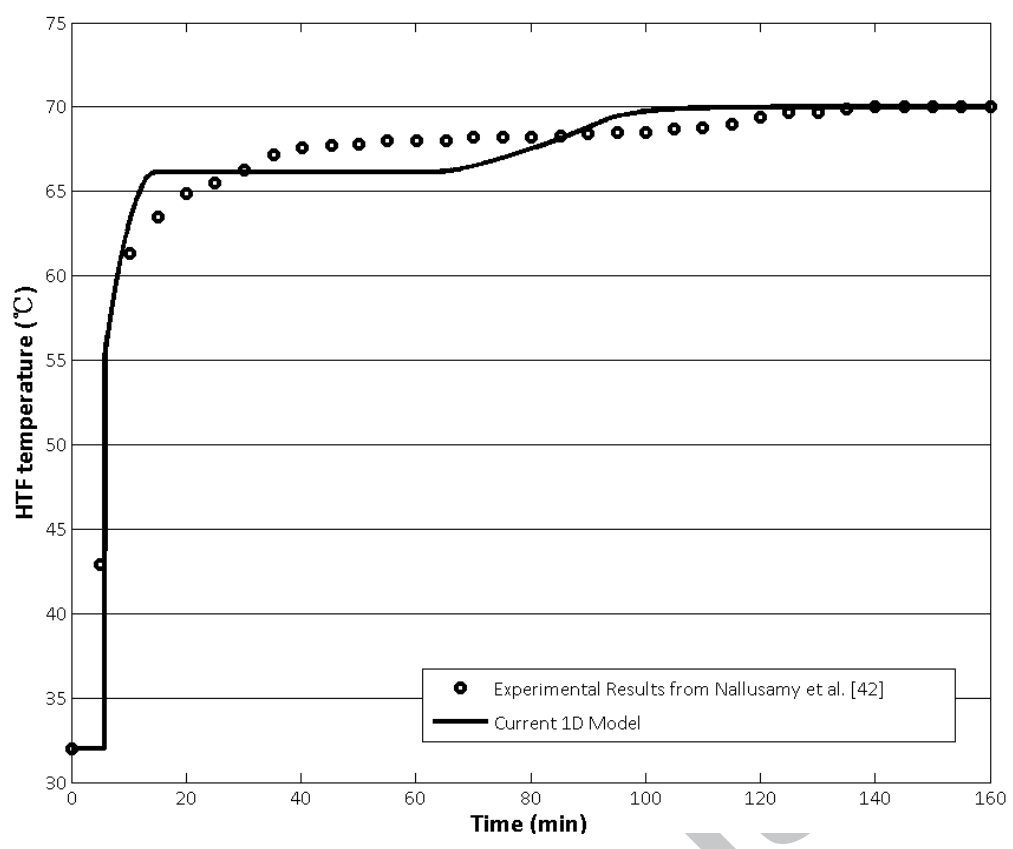

Fig. 2 Comparison of fluid temperature located at the middle of the tank

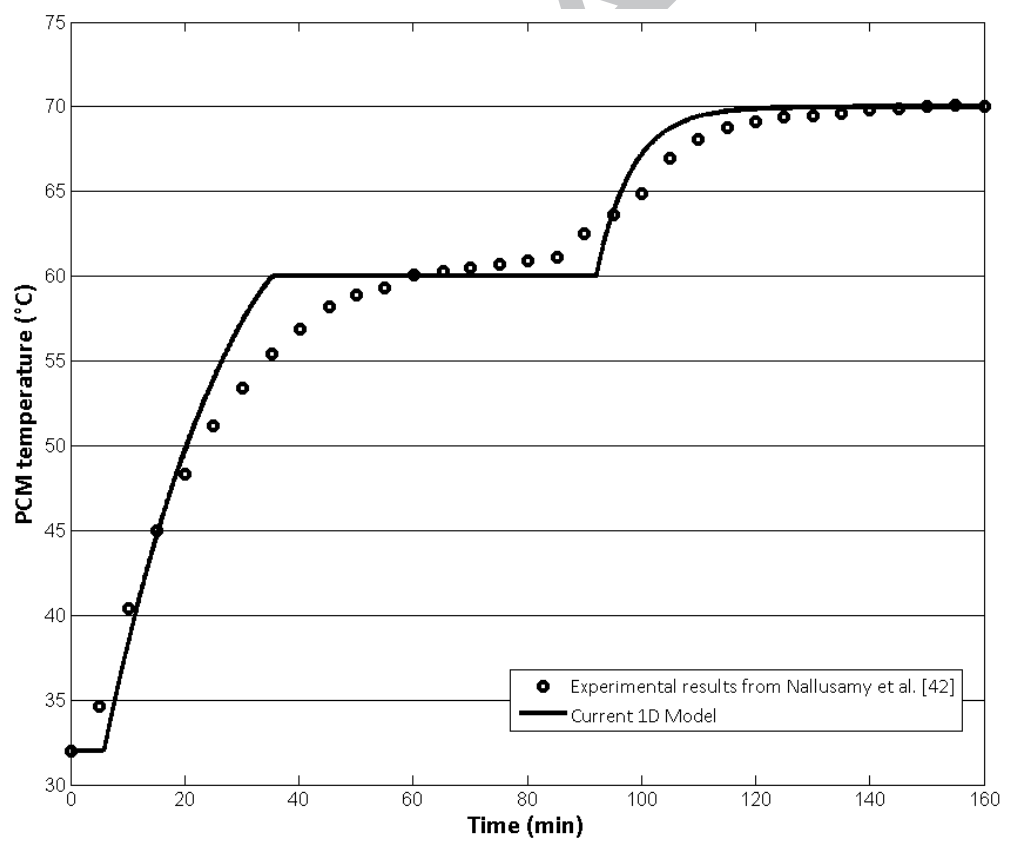

Fig. 3 Comparison of PCM temperature located at the middle of the tank

It is worth noting that the current model does not consider any heat loss from the tank due to the assumption of perfect thermal insulation. This will cause more or less discrepancy between the simulation and test results. Studies about the influence of heat loss to the temperatures in the thermal storage tanks have been reported by Modi and Pérez-Segarra [43]. The heat loss at the tank surface needs a certain length of time to penetrate and influence the temperature of the center of the tank. Nevertheless, the currently proposed 1D model has the capacity to incorporate 
the heat loss by adding a heat loss term on the right hand side of Eq. (1), almost with no sacrificing the computational efficiency.

\subsection{A generalized approach to determine the storage tank volume}

Before the actual storage tank volume is determined a trial storage tank volume needs to be calculated, which will be used as a basis for the general volume sizing. We should also know all the required properties of HTF and PCM, the operational parameters (such as inlet fluid flow rate and temperature), and the chosen radius $(R)$ of the storage tank. The only remaining unknown parameter is the height of the storage tank. From hereafter, finding the height of the storage tank is viewed as sizing the tank volume, as it can be calculated easily using the height and radius of the tank. Here the trial storage tank height is calculated assuming a discharge process starts for a storage tank that is initially fully charged with a referenced enthalpy of PCM at $T_{H}$. Under this situation, the trial height of the tank should satisfy the requirement of the temperature of HTF during a desired discharging time period. Details of this approach will be discussed in the following sections.

The way to define the dimensionless time in the dimensionless governing equations (Eq. (7) and (8)) is to set the reference time scale as $t_{r e f}=H / U$, which is a case-dependent definition. To define a general characteristic time scale, the reference time scale should be carefully chosen. Reviewing the dimensionless governing equations shows that the dimensionless parameter $\tau_{r}$ is the only term with dimensional dependence, if a new set of variables is applied to the dimensionless equations for Eq. (7) and (8):

$$
\tilde{t}=t^{*} / \tau_{r}, \quad \tilde{z}=z^{*} / \tau_{r}
$$

which allows $\tau_{r}$ to be absorbed into the time and spatial variables. The dimensionless governing equations of Eq. (7) and (8) in this new domain, which will be used for profiles invariant of tank dimensions, will become:

$$
\begin{gathered}
\frac{\partial \theta_{f}}{\partial \tilde{t}}+\frac{\partial \theta_{f}}{\partial \tilde{z}}=\left(\theta_{r}-\theta_{f}\right) \\
\frac{d \eta_{r}}{d \tilde{t}}=-\frac{H_{C R}}{\theta_{r_{-} \text {melt }}}\left(\theta_{r}-\theta_{f}\right)
\end{gathered}
$$

with spatial and time domain as follow:

$$
0 \leq \tilde{t} \leq \tilde{t}_{\text {final }}, 0 \leq \tilde{z} \leq \tilde{z}_{\text {final }}
$$

where $\tilde{t}=t \frac{h_{e f f} S r}{\rho_{f} C_{f} \varepsilon A_{t a n k}}=\frac{t}{t_{C}^{*}}, \tilde{z}=z \frac{h_{e f f} S r}{C_{f} \dot{m}}=\frac{z}{z_{C}^{*}}, t_{C}^{*}=\frac{\rho_{f} C_{f} A_{r}}{h_{e f f} S r}$, and $z_{C}^{*}=\frac{C_{f} \dot{m}}{h_{e f f} S r}$.

Using this new set of dimensionless equations, Eq. (12) and (13), along with the assumption of a fully charged tank initially, a single discharge run with the model can be conducted to determine the trial storage tank height based on the desired cutoff HTF temperature, below which HTF will not be considered for heat extraction. With respect to the modified characteristic time constant $t_{C}^{*}$, the code can run as long as necessary to obtain temperature profiles at 
the real times desired. The spatial domain, however, is no longer fixed at a dimensionless value of 1.0, and can run as long as desired, where a run with a longer spatial domain will be able to represent a taller tank. The modified characteristic space constant $z_{C}^{*}$ again governs the real storage tank height corresponding to the dimensionless value.

Application of this modification to the code follows simply. If the parameter $\tau_{r}$ is set equal to 1.0 rather than calculated based on thermoproperties of HTF and filler material, the model works with the new set of governing equations as Eq. (12) and (13). It must be recognized that the dimensionless time and space are now of the new convention and domain. Having chosen a cross sectional area and mass flow rate, and calculating the dependent terms as necessary, the dimensionless time corresponding to the desired output time is found simply as:

$$
\tilde{t}_{\text {desired }}=\frac{t_{\text {desired }}}{t_{C}^{*}}
$$

Having obtained the 'sizing' temperature profiles at all instances in time, we turn to the profile at the calculated desired dimensionless time. The 'variable boundary' convention allows us to selectively cut off the output fluid temperature profile at our desired limit at this instance in time. In this sense, the dimensionless spatial value at which the profile intersects the minimum allowed output fluid temperature $\theta_{f_{-} \text {desired }}$ defines the trial tank height, according to:

$$
\tilde{H}=z=\tilde{z}_{H} \cdot z_{C}^{*}
$$

Therefore, the trial storage tank volume is:

$$
\tilde{V}=\tilde{H} \cdot \pi R^{2}
$$

After introducing the general volume sizing strategy for LHSS, this trial tank height $\tilde{H}$ or trial storage tank volume $\tilde{V}$ will be used as the basis for further considerations and comparisons.

\subsection{Energy storage efficiency}

If an energy-carrying fluid medium in a thermal storage system can be withdrawn at its temperature originally being stored, the system has the highest efficiency, or has zero exergy loss from point of view of thermodynamics [44]. Such a thermal energy storage system may be idealized by using two separated storage tanks, or by using a single storage tank with an ideal thermal insulation baffle (movable along the height of the tank) in between the hot fluid and cold fluid. The ideal thermocline heat delivery efficiency may be considered as 1.0 since it has no exergy loss.

However, for a thermal storage tank with encapsulated filler material, based on the work of Li et al. [17], the energy delivered in the required time period at a required mass flow rate is always less than that of the ideal energy delivery in an ideal thermocline tank. If the required heat discharging period is $t_{\text {ref,discharging }}$, an energy storage efficiency can be defined as: 


$$
\eta=\frac{\int_{0}^{t_{\text {ref,discharging }}}\left[T_{f}(z=H, t)-T_{L}\right] d t}{\left(T_{H}-T_{L}\right) \cdot t_{\text {ref,discharging }}}
$$

where the numerator represents the energy discharged from the actual tank, and the denominator represents the energy discharge from an ideal thermocline tank.

The dimensionless form of the required time period of energy discharge is defined as:

$$
\Pi_{d}=\frac{t_{\text {ref,discharging }}}{H / U}
$$

Substitute the dimensionless energy discharge period $\Pi_{d}$ into Eq. (18), the energy storage efficiency is determined by:

$$
\eta=\frac{\int_{0}^{\Pi_{d}} \theta_{f}\left(z^{*}=1, t^{*}\right) d t^{*}}{\Pi_{d}}
$$

\section{General Volume Sizing Strategy for Latent Heat Storage System (LHSS)}

To satisfy the requirement of above cutoff temperature in heat discharge, an actual storage tank volume needs to be determined with respect to the operational parameters and thermal properties of HTF and PCM, including: the electrical power, the thermal efficiency of the power plant, the extended period of operation of charge/discharge, the required high temperature of heat transfer fluid from the storage tank, the low temperature of fluid returned from the power plant, the properties of HTF and PCM, the nominal radius of filler material if applicable, as well as the void fraction in a storage tank.

On the basis of trial storage tank volume $\tilde{V}$, as discussed previously in Section 2.2, for a CSP plant using a particular PCM as storage material, $\tilde{V}$ (or $\tilde{H}$ with a prefixed storage tank radius $R$ ) can easily be substituted into the computation code for solving the governing equations, and the computation may run until the presumed number of charge/discharge cycles are done. If examining the output HTF temperatures for a 6 hours' discharge after several charge/discharge cycles, one can find that typically the HTF cannot satisfy the cutoff temperature in the entire period, although exceptions still exist. The reason the trial tank height usually cannot fully meet the cutoff temperature requirement is that before the cyclic steady state is reached more energy is extracted from LHSS than the energy being stored. The conditions for trial tank volume sizing differ from the cyclic operations since only one discharge has been processed immediately after a fully charged state in the former case. Obviously, more energy can be extracted in this case than that at a cyclic steady state. Therefore, the trial storage tank height usually cannot meet the goal of cutoff temperatures in the entire discharge period. For some special cases, however, if the PCM has an extremely large latent heat of fusion and the melting temperature is exactly equal to the cutoff temperature, its output HTF temperature will be above or equal to the cutoff temperature during the entire discharge time period, as illustrated in Ref. [45]. 
In order to obtain a better thermal performance by satisfying the criterion of cutoff HTF temperature, there are three options one can choose if all other operational conditions are known: (a) enlarging the trial storage tank volume; (b) increasing the mass flow rate of HTF; or (c) extending the heat charge time. Among these three options, enlarging the trial storage tank volume is the primary choice. However, if the storage system still cannot supply HTF above the cutoff temperature during the entire time period of discharge, the second choice of extending the heat charge time has to be taken into consideration, and this is actually a reasonable and easy approach in some areas with abundant solar resources. The last choice is to increase the mass flow rate of HTF, with the consequence of enhancing heat transfer between HTF and encapsulated PCM. This approach seems reasonable, however to do so, auxiliary solar field is required for extra HTF to absorb and store the heat, and the match between primary system and auxiliary system is difficult.

To this point, a generalized strategy of volume sizing for LHSS has been completely outlined, a flow chart of this sizing strategy has been plotted in Fig. 4, and the computation procedures from the flow chart are apparent. For convenience of designing and analysis, a description of the computation steps in Fig. 4 is provided below.

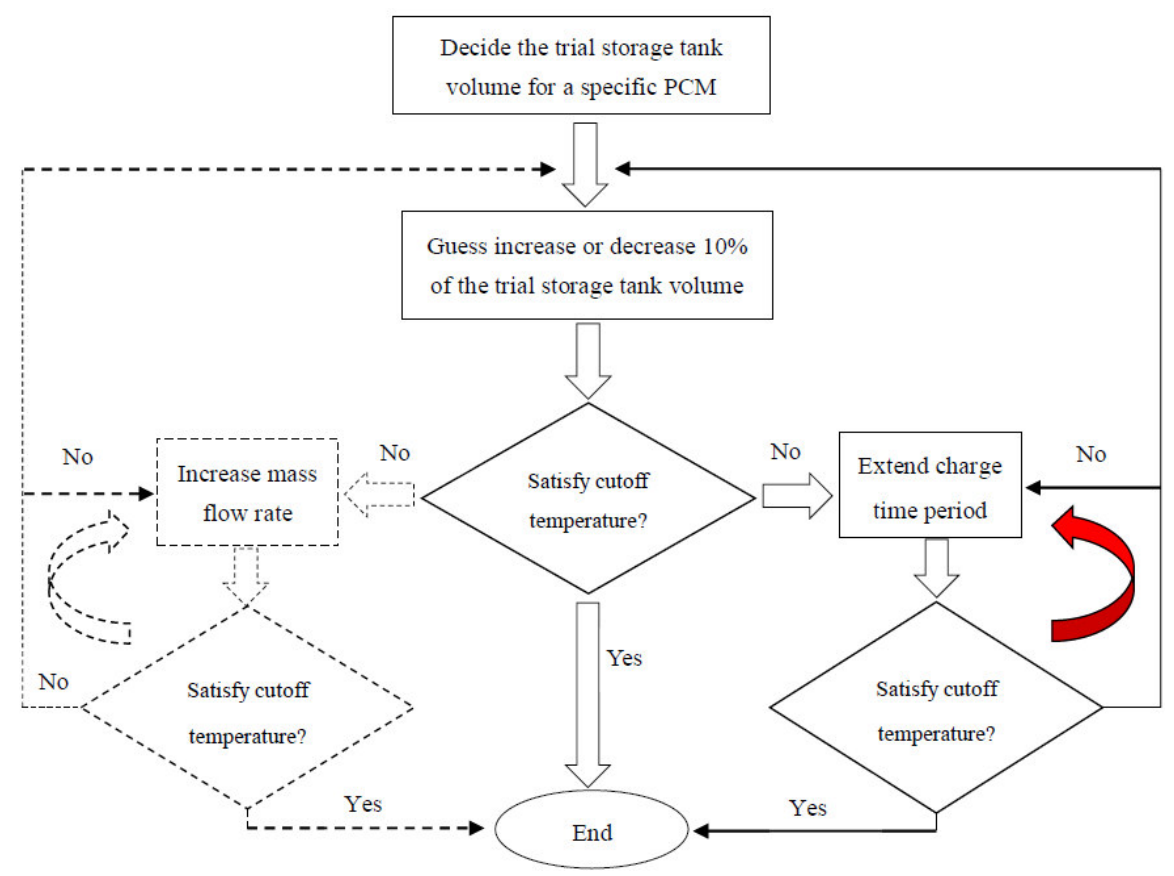

Fig. 4 Flow chart of general volume sizing strategy for LHSS

\section{Step 1: Decide the trial storage tank volume for a specific PCM}

This is the initial step in the standard computation procedures as shown in the flow chart, and the trial storage tank volume $\tilde{V}$ (or trial storage tank height $\tilde{H}$ with a prefixed storage tank diameter $D$ ) for a particular PCM will be determined by the properties of the HTF and PCM as well as operational parameters, according to the method introduced in Section 2.3. 


\section{Step 2: Assume an increase or a decrease in the trial storage tank volume}

Once $\tilde{V}$ or $\tilde{H}$ is determined from Step 1, it is given to the code so that the temperature of the outflow HTF during 6 hours of discharge can be easily computed. For the cyclic steady operation, if the outflow HTF temperature cannot be maintained above the cutoff temperature during a discharge process, improvement to the storage system is inevitable. Enlarging the volume of storage tank, for example 10\%, would be the next starting point. Substituting the increased tank volume into the code, the modeling computation will run until the cyclic steady charge/discharge operation is reached. The temperature of the outflow HTF during a discharge process of 6 hours is checked to meet the target of larger than the cutoff temperature. If the answer is yes, then the calculation is accomplished and the required storage tank volume is obtained. Usually, this trial-and-error process is repeated for multiple times to finally decide a tank volume. As shown in the flow chart of volume sizing process, increase of tank volume alone may not enough to satisfy the requirement of desired temperature of outflow HTF in a required period of time. Therefore, on top of an increased tank volume, increase of charging time or increase of flow rate of charging process are two options that can finally meet the requirement of desired outflow HTF temperature in a required period of time. These two options are discussed hereafter.

\section{Sub-step 1: Increase the mass flow rate of HTF}

The increase of the mass flow rate of HTF during the charging process enhances the heat transfer between HTF and encapsulated PCM, and also carries more energy into the storage tank. Therefore, the outflow HTF temperature in a discharging process will be increased to above the cutoff temperature in the entire discharging period. Sub-step 1 is plotted in Fig. 4 and marked with dashed lines. In this case the volume sizing flow chart includes volume increase and flow rate increase for the charging process. If the increase of mass flow rate cannot achieve the goal, then a larger increase of the volume of storage tank is needed, which then is followed by a trial of increase of flow rate of HTF during the charging process. Nevertheless, choosing a larger flow rate may need a larger solar collection field and is not cost effective.

\section{Sub-step 2: Extend charging time.}

Compared to Sub-step 1, extending the charging time is a more reasonable approach to achieve the goal. According to the target set by the DOE SunShot Initiative, 6 hours discharge time is the minimum requirement. If we give just 6 hours for charging time to the system, it may not satisfy the cutoff temperature during the discharge due to the fact that insufficient energy has been stored. However, if the charging time is extended to 7 hours or more, (for example, in some areas with abundant solar resources, 8 hours charge time is possible) it will be easier to achieve the goal. With a limited increase of tank volume, a dramatic extension of charge time may still unable to achieve the goal. In this case, an extra increase of tank volume is needed and the computation steps of increasing of charging time are followed until the desired temperature of HTF (above a cutoff temperature) in the desired discharging time is met. In this study, volume increase and Sub-step 2 will be adopted to size the volume of storage tank with a reasonably extended charging time period. 
The above three steps and two sub-steps of generalized volume sizing strategy will provide a guideline for engineers to design a CSP plant incorporated with an energy storage system using PCM. In the general volume sizing strategies presented in Ref. [40] and [41], a discharge efficiency was used to determine the storage tank height. In the current model, the cutoff temperature is the chosen criterion, which is more practical in a real CSP plant. It is important to note that in this study, Sub-step 1 will not be considered, because a constant mass flow rate is a basic condition defined for a CSP plant.

In the following section, a thermal energy storage system for a CSP plant with $60 \mathrm{MW}$ electrical power output will be sized following the currently proposed general volume sizing strategy. The actual storage volume and charging time will be decided at the end.

\section{Results and Discussion}

\subsection{Descriptions of the example}



Fig. 5 System schematic of a 60 MW parabolic trough CSP plant (Source: [46])

A parabolic trough CSP plant with $60 \mathrm{MW}$ electrical power output at the thermal efficiency of $35 \%$ is taken as an example, as shown in Fig. 5, based on the systematic design by Biencinto et al. [46]. The HTF used in the solar field is Therminol VP-1. The power plant requires high and low fluid temperatures of $390{ }^{\circ} \mathrm{C}$ and $310{ }^{\circ} \mathrm{C}$, respectively. Two different types of PCMs are used as filler materials. Depending on the packing scheme, the void fraction $\mathcal{E}$ in a packed bed with spheres of a fixed diameter ranges from 0.26 to 0.476 [47]. In this paper, a void fraction of 0.3 was chosen for all the calculations. The diameter of the encapsulated PCM is $4 \mathrm{~cm}$, and the radius of the storage tank is set as $5 \mathrm{~m}$. The required minimum time period of energy discharge is 6 hours, based on the U.S. Department of Energy's SunShot Initiative [34]. The thermal storage system is assumed to be operated within 100 days or 100 charge/discharge cycles without maintenance. The minimum cutoff temperature is set to be $360{ }^{\circ} \mathrm{C}$ in a discharge process, below which HTF cannot be effectively used for power generation. This cutoff temperature is based on the conclusion from Modi and Pérez-Segarra [43] that $30^{\circ} \mathrm{C}$ below the high temperature is acceptable. All the operating conditions and the properties of HTF and filler material are listed in Table 1 and 2. It's important to note that choosing two kinds of PCMs is not to compare their thermal performance, but to demonstrate how the general strategy is applied to different cases with different storage materials. However, as a result, it gives two 
choices to engineers who need to design the thermal storage system. A detailed comparison of thermal performance of using different PCMs and parametric study will be presented in a separate paper in the future.

\section{Table 1 Operational parameters of a $60 \mathrm{MW}$ CSP plant}

\begin{tabular}{llll}
\hline$P_{\text {ele }}=60 \mathrm{MW}$ & -Total electrical output & $\xi=35 \%$ & - Thermal efficiency \\
$R=5 \mathrm{~m}$ & -Radius of storage tank & $T_{\text {cutoff }}=360{ }^{\circ} \mathrm{C}$ & - Cutoff temperature \\
$T_{H}=390{ }^{\circ} \mathrm{C}$ & - High temperature & $T_{L}=310{ }^{\circ} \mathrm{C}$ & - Low temperature \\
$N_{\text {cycle }}=100$ & -Number of cycles & $\Delta t_{\text {discharge }}=6 \mathrm{~h}$ & - Time period of discharge \\
$\varepsilon=0.3$ & - Void fraction & $d_{r}=0.04 \mathrm{~m}$ & -Diameter of filler material
\end{tabular}

Table 2 Properties of HTF and filler materials

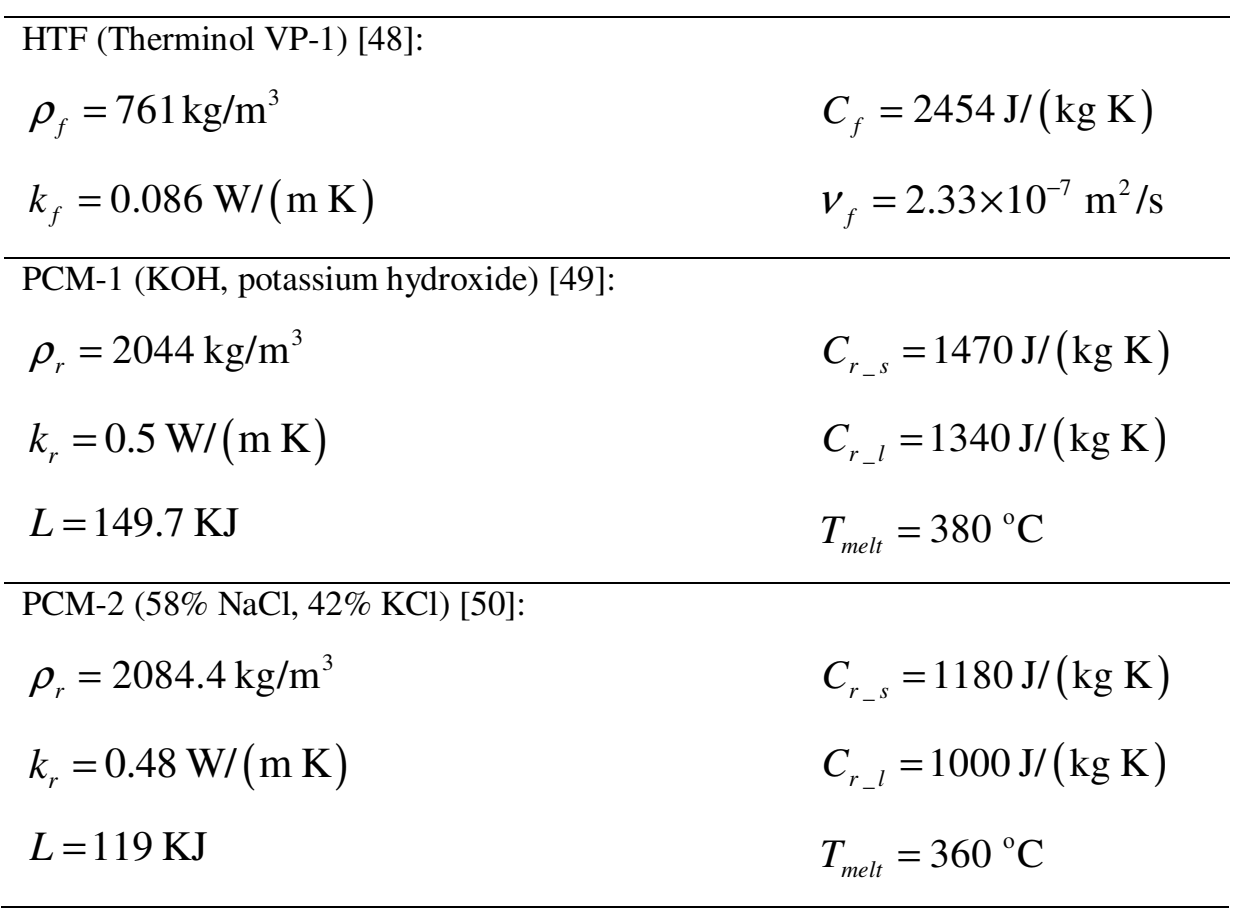

Based on the properties provided above and Eq. (21) below, one can calculate a necessary total mass flow rate for the thermal storage as follows:

$$
\frac{P_{\text {ele }}}{\eta}=\dot{m}_{\text {total }} \cdot C_{f}\left(T_{H}-T_{L}\right)
$$

The required total mass flow rate for a $60 \mathrm{MW}$ electrical supply is calculated as $\dot{m}_{\text {total }}=873.21 \mathrm{~kg} / \mathrm{s}$, which can then be divided into four sub-streams, and the mass flow rate $\dot{m}$ in each sub-stream is thus equal to $218.3 \mathrm{~kg} / \mathrm{s}$. The reason for dividing the total HTF stream into four is to make sure the Reynolds number will be in the proper range 
so that Eq. (5) can be applied to determine the intrinsic heat transfer coefficient. In the following calculations, only one sub-stream will be studied, since the results for one sub-stream will be identical to the other three sub-streams.

Next, the first step in the general strategy as illustrated in the flow chart of volume sizing (Fig. 4) will be followed to find the trial thermal storage tank volume for each PCM in Table 2.

\subsection{A trial storage tank volume}

The radius for the storage tank is set as $5 \mathrm{~m}$ in this analysis. On the basis of the provided thermal properties of HTF and PCMs in Table 1 and Table 2, a tank height $\tilde{H}$ is the only unknown parameter to determine the trial storage tank volume $\tilde{V}$, where $\tilde{V}=\tilde{H} \cdot \pi R^{2}$. According to the definition of dimensionless temperature, a cutoff temperature of $360{ }^{\circ} \mathrm{C}$ means its dimensionless value is equal to 0.625 . Following the generalized approach introduced in Section 2.3, the trial storage tank height can easily be determined, and the computational results are shown in Fig. 6 as follows.

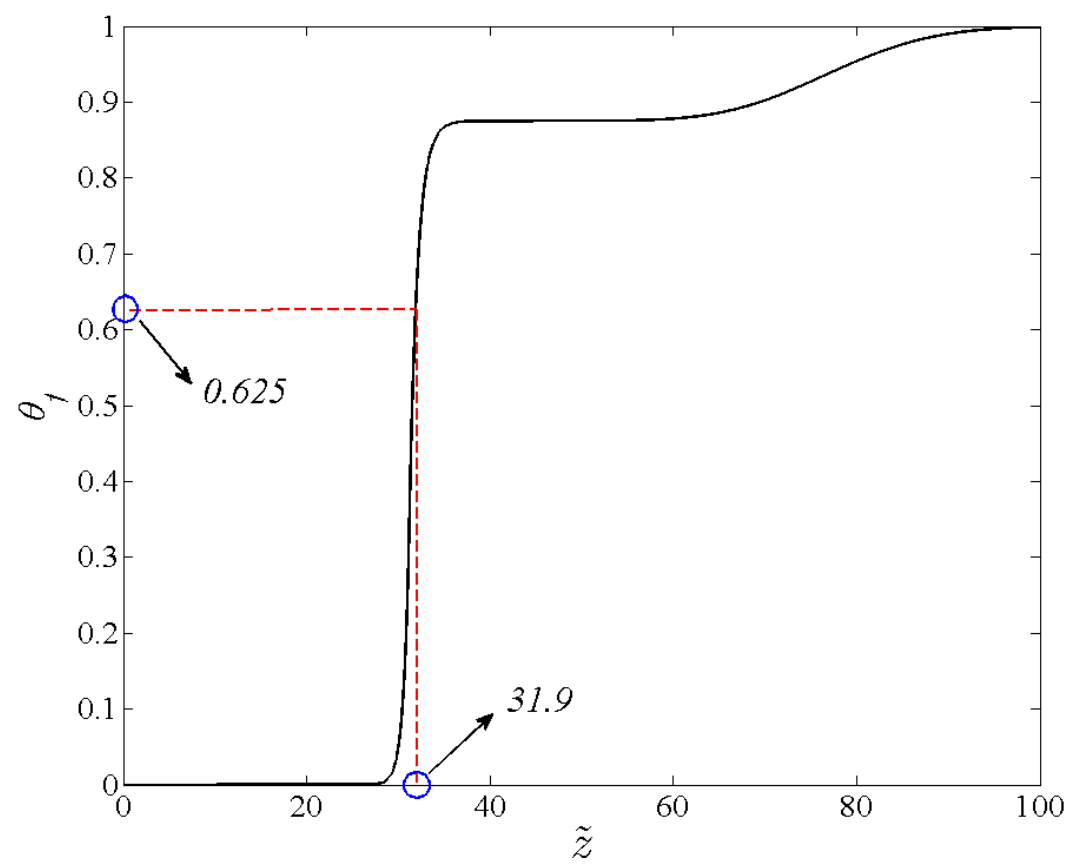

(a) PCM-1 


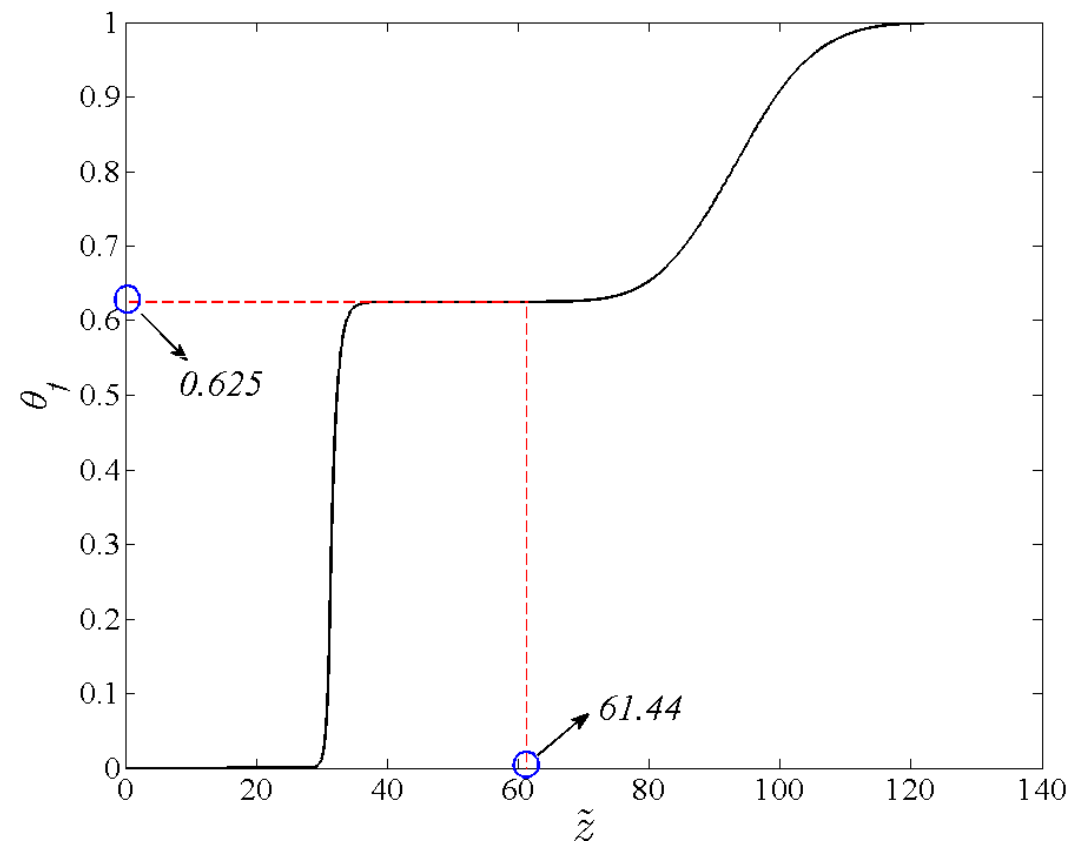

(b) $\mathrm{PCM}-2$

Fig. 6 Storage tank sizing for each PCM at dimensionless melting temperature of 0.625

The dimensionless height of storage tank can be determined when the dimensionless HTF temperature reaches 0.625, as seen in Fig. 6. Based on the modified characteristic space constants calculated from Eq. (15), the dimensional tank height for each PCM can be calculated easily using Eq. (16), and the results are shown in Table 3.

Table 3 Height of trial storage tank for each PCM when the cutoff temperature is $360^{\circ} \mathrm{C}$.

\begin{tabular}{l|c|c}
\hline \multicolumn{1}{c|}{ PCMs } & $z_{C}^{*}$ & Dimensional height of trial tank \\
\hline PCM-1 $(\mathrm{KOH})$ & $0.81 \mathrm{~m}$ & $25.9 \mathrm{~m}$ \\
\hline PCM-2 $(58 \% \mathrm{LiCl}, 42 \% \mathrm{KCl})$ & $0.83 \mathrm{~m}$ & $51.2 \mathrm{~m}$ \\
\hline
\end{tabular}

The next calculation uses the height of trial storage tank in Table 3. All other operational parameters are exactly the same as in Table 1. The charge time period initially is set to be equal to discharge time period (6 hours). The modeling computation for the thermal performance of the storage system can be obtained for the two different PCMs. In the next section, the results for PCM-1 will be examined to obtain an actual storage tank volume, following the general volume sizing strategy.

\subsection{Volume sizing for thermal storage system using PCM-1}

As a first step, the temperature of outflow HTF versus discharge time at cyclic periodic steady state has been plotted in Fig. 7, in which the red, dashed line represents the cutoff temperature. 


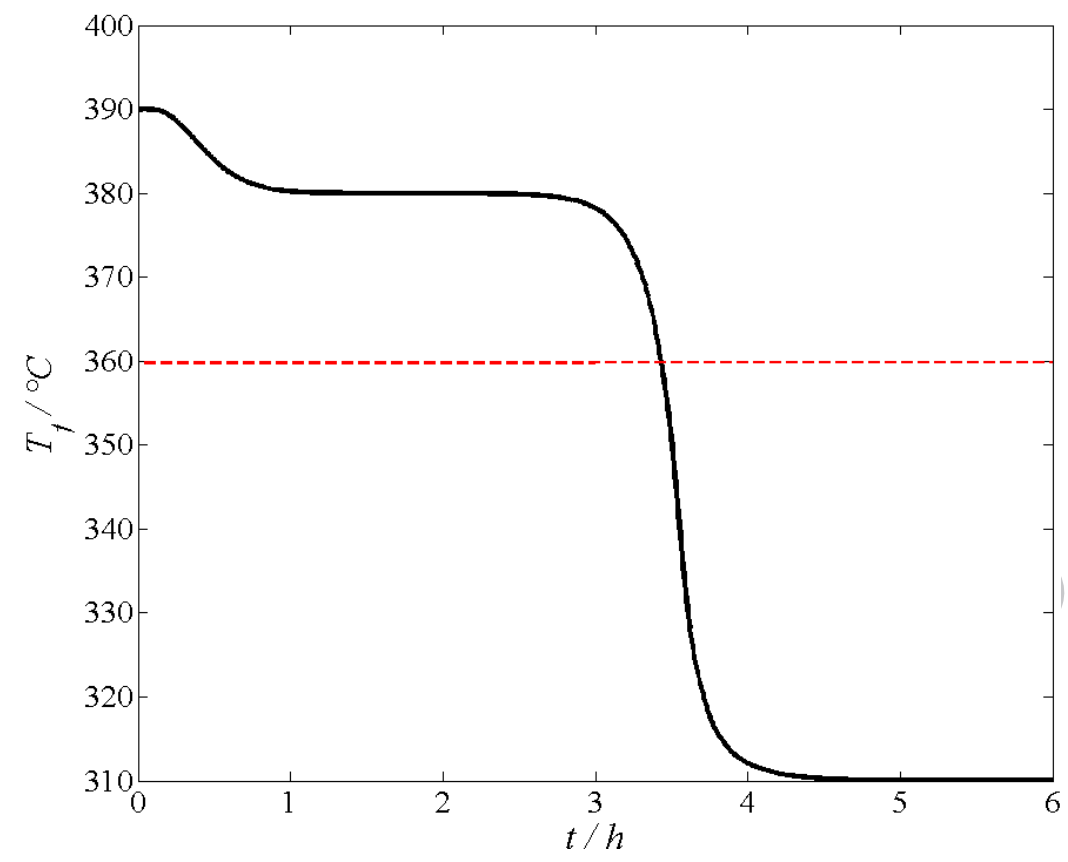

Fig. 7 Temperatures of outflow HTF in 6 h discharge based on the height of the trial storage tank for PCM-1

It can be observed clearly from Fig. 7 that the storage system using PCM-1 can only supply HTF above $360{ }^{\circ} \mathrm{C}$ for approximate 3.5 hours, which is much less than the required 6 hours. Therefore, based on the general volume sizing strategy, the volume of the trial storage tank is increased by $10 \%$ in Step 2. Then, the Sub-step 2 is carried on by extending the charging time from 6 hours to 8 hours, and a comparison is made with the case of only the trial tank volume in respect to the output HTF temperatures. The results are shown in Fig. 8.

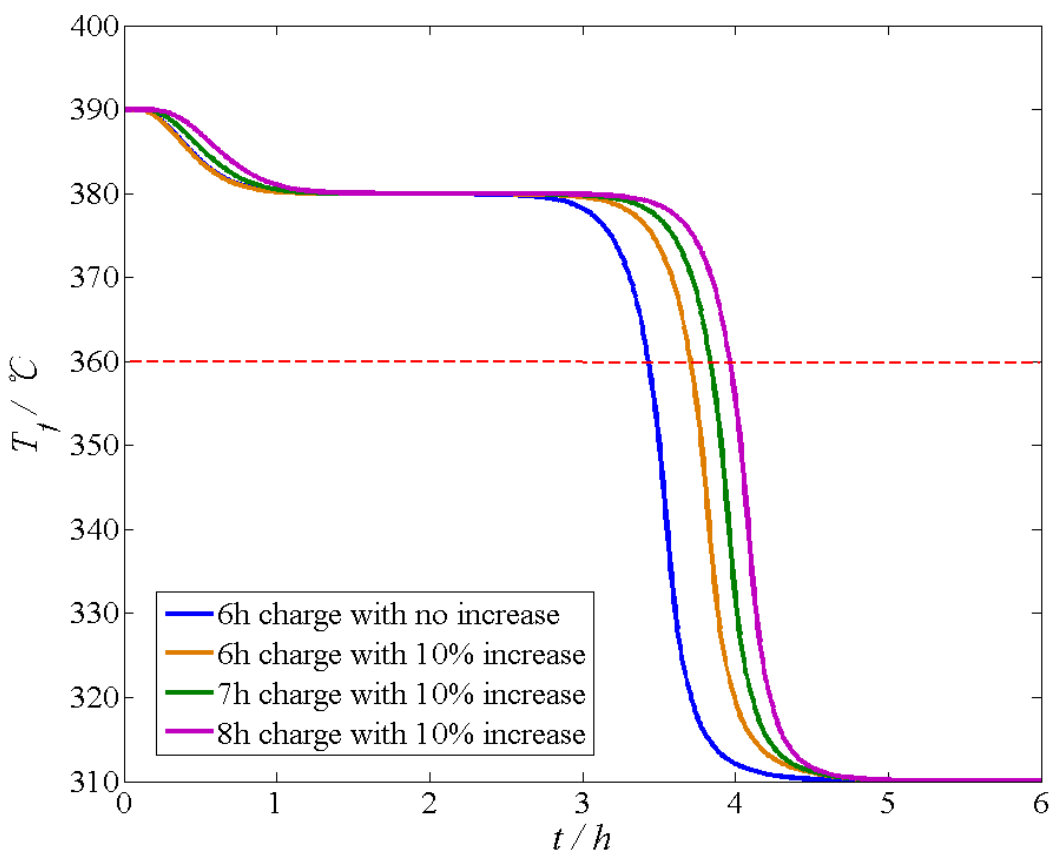


Fig. 8 Output HTF temperature in $6 \mathrm{~h}$ discharge by varying charge time from $6 \mathrm{~h}$ to $8 \mathrm{~h}$ with $10 \%$ increase of the height from trial storage tank for PCM-1

Figure 8 shows the comparison of output HTF temperatures within 6 hours discharge by varying charging time from 6 hours to 8 hours and a 10\% increase of height from the trial storage tank. One can easily see from this figure that even if the charging time is extended to 8 hours, the $10 \%$ increase of the tank height from the trial tank height still would not fully meet the cutoff temperature of above $360{ }^{\circ} \mathrm{C}$ in 6 hours. It is clear that 6 hours' charge with $10 \%$ increase of the tank volume can make the discharged fluid temperature only last for about 3.8 hours. The 7 hours' charge with $10 \%$ increase of volume can discharge HTF for about 3.9 hours with the temperature above $360{ }^{\circ} \mathrm{C}$, while the longest time period of 4.1 hours is offered by 8 hours charge. Even though these results are better than that of 6 hours' charge at only trial tank volume, it's still far from the target of entire 6 hours' supply of fluid at temperatures above $360{ }^{\circ} \mathrm{C}$. As a result, the next step is to go back to Step 2 by increasing another $10 \%$ or more of the trail storage tank volume. Following that, the charging time is now chosen as 8 hours. The comparison is shown in Fig. 9.

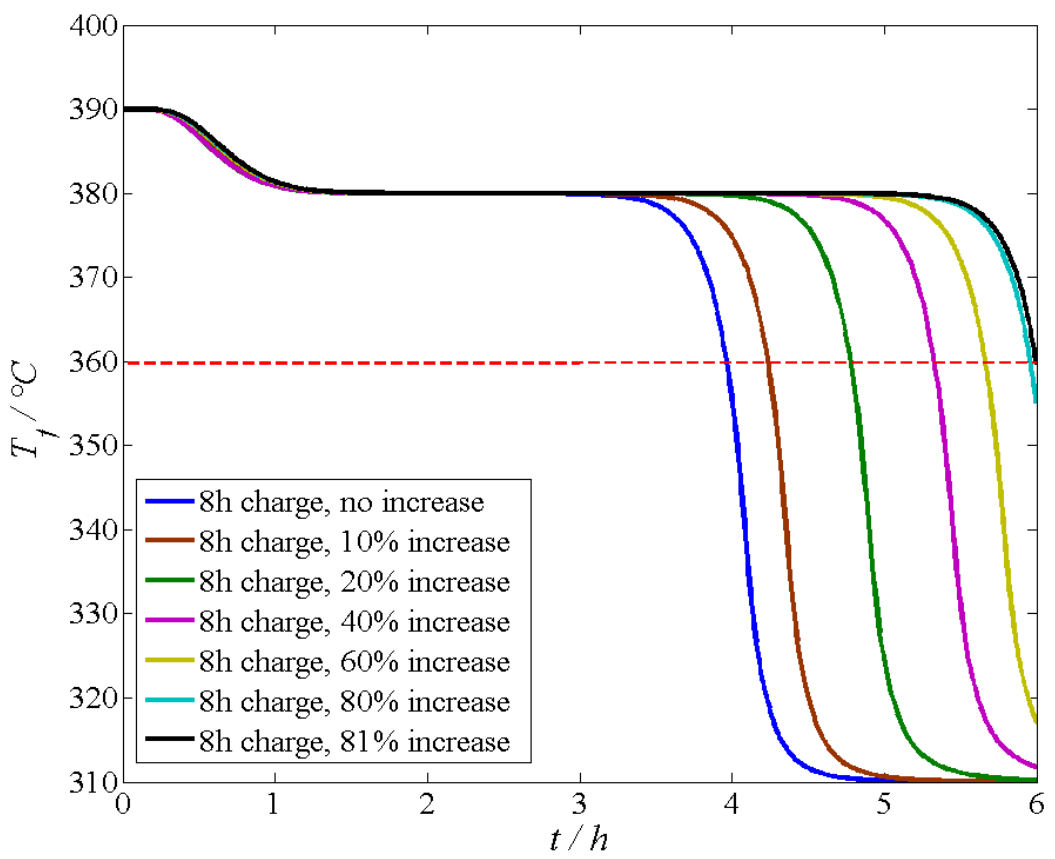

Fig. 9 The output HTF temperature in $6 \mathrm{~h}$ discharge with enlarged volume from the trial storage tank volume and 8 $h$ charging time for PCM-1

Figure 9 demonstrates the output HTF temperature within 6 hours' discharge, based on enlarged volume from the trial storage tank volume and a fixed charging time of 8 hours for PCM-1. It is seen clearly from this figure that before the volume having an $80 \%$ increase, the output HTF temperature at the end of 6 hours of discharge is far away from the cutoff temperature of $360{ }^{\circ} \mathrm{C}$. In the next step, $81 \%$ increase of the tank volume and 8 hours' charging time were considered. The results of discharged fluid temperature could completely satisfy the requirement 
of above $360{ }^{\circ} \mathrm{C}$ during the entire discharging time period of 6 hours. For this result, the storage tank volume is $3683.5 \mathrm{~m}^{3}$, which may need multiple tanks in a total height of $46.9 \mathrm{~m}$, if the radius of each tank is fixed at $5 \mathrm{~m}$. Based on Eq. (20), the energy storage efficiency for such a LHSS is $88.19 \%$.

For the same thermal storage requirement and PCM material, if the solar radiation collection time cannot be longer than 6 hours, the only option to meet the requirement is to further enlarge the trial storage tank volume. Fig. 10 portraits the comparison of output HTF temperature during a 6 hours' discharge with various storage tank volumes at a fixed 6 hours of charge. One can observe from this plot that only when a $90 \%$ increase of the volume is employed, the output HTF temperature at the end of 6 hours' discharge can get close to $360{ }^{\circ} \mathrm{C}$. At the end of the computation, a $94.5 \%$ increase of the trial storage tank volume was found to meet the requirement that the discharged fluid temperature is above $360{ }^{\circ} \mathrm{C}$ during entire discharge time period of 6 hours. For this result, the tank volume is $3954.2 \mathrm{~m}^{3}$, and the total height of multiple tanks is $50.4 \mathrm{~m}$ if the storage tank radius is fixed at $5 \mathrm{~m}$. According to Eq. (20), the energy storage efficiency for such a LHSS is $87.61 \%$. This efficiency is close to that of the last case which has energy storage efficiency of $88.19 \%$. This means that with larger volume of the storage tank, one can use shorter charge time of 6 hours to achieve the same goal.

The above two cases show that the general volume sizing strategy offers designers multiple options to decide an appropriate storage tank volume and operation scheme to maintain the HTF temperature above the cutoff temperature during a required 6 hours of discharge.

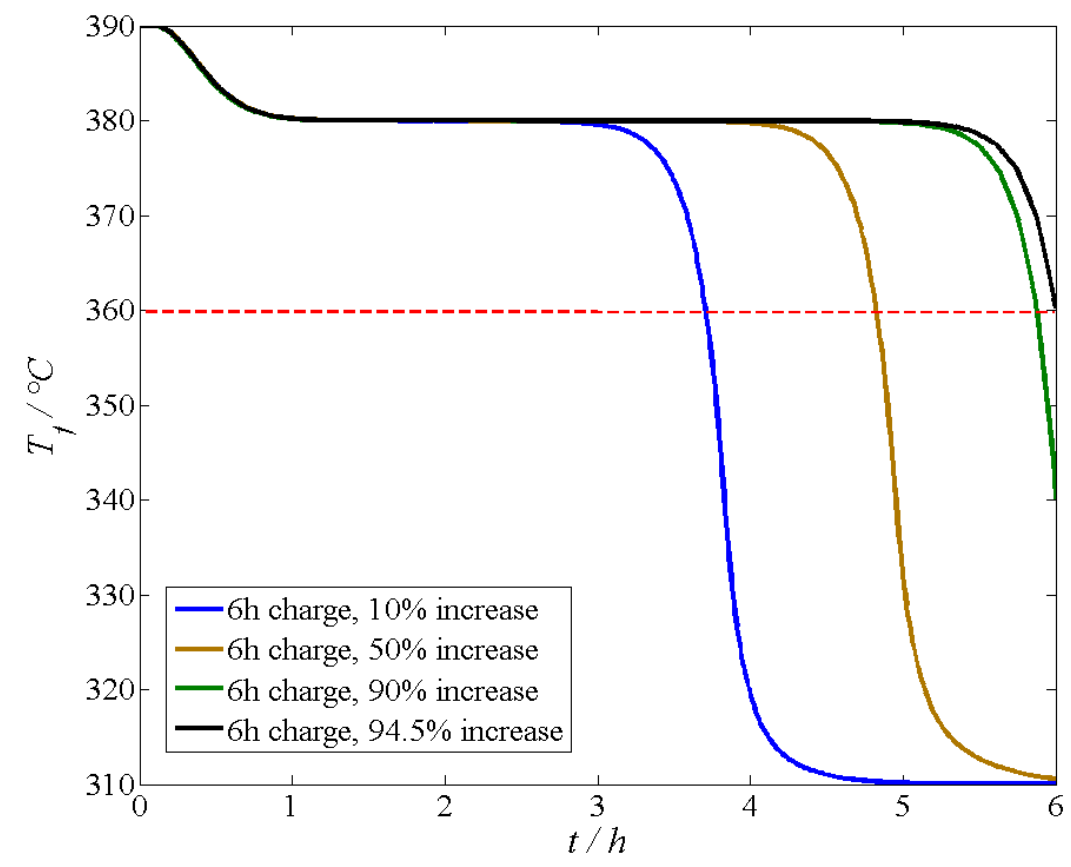

Fig. 10 The output HTF temperature in $6 \mathrm{~h}$ discharge with enlarged volume of storage tank and $6 \mathrm{~h}$ charge for

$P C M-1$

\subsection{Volume sizing for thermal storage system using PCM-2}


This is another example to demonstrate the application of the general volume sizing strategy for the same thermal storage requirement using a different PCM. Following Step 1 in the flow chart of volume sizing, the trial storage tank height for PCM-2 is obtained, which is $51.2 \mathrm{~m}$, as shown in Table 3. The trial storage tank volume is $4021.2 \mathrm{~m}^{3}$, for a fixed radius of storage tank of $5 \mathrm{~m}$. This data of volume will be substituted to the modeling computation to check if the output HTF temperature can be maintained higher above the cutoff temperature of 360 ${ }^{\circ} \mathrm{C}$ in cyclic steady operation. The result is shown in Fig. 11, in which the red dashed line is the cutoff temperature.

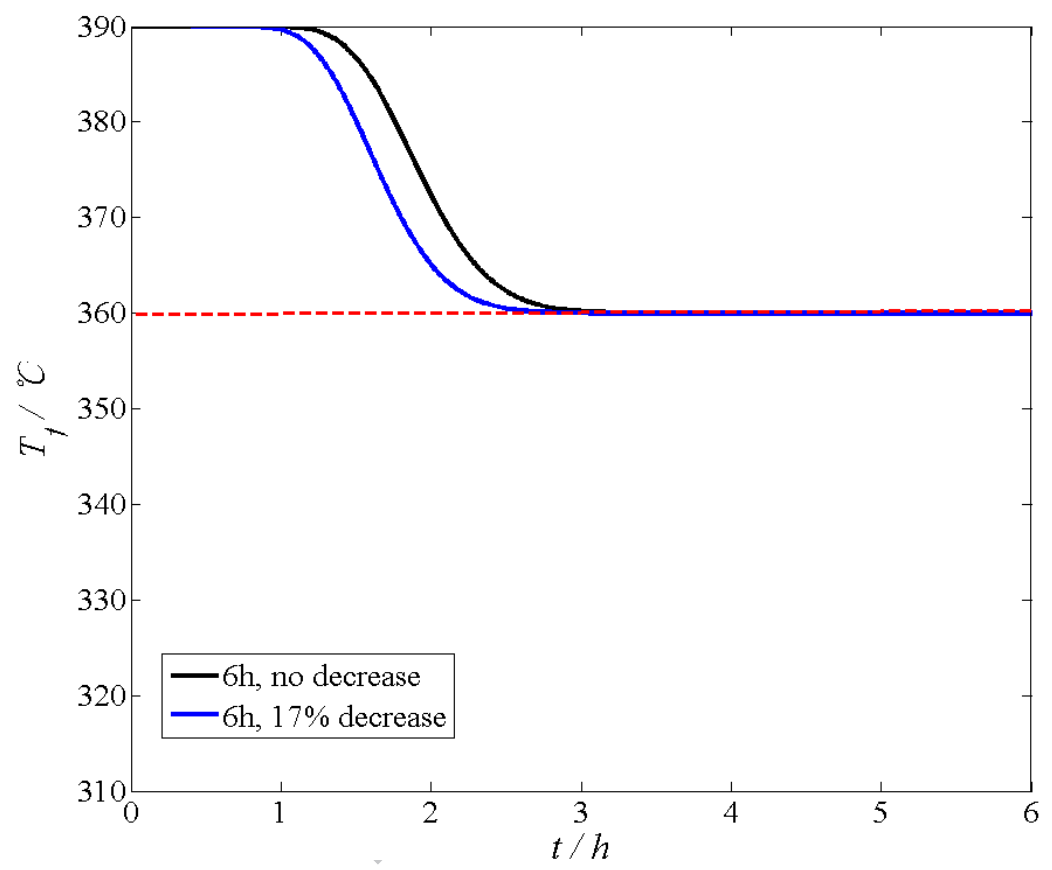

Fig. 11 The output HTF temperature in 6 h discharge with the trial storage tank height and 6 h charge for PCM-2

Figure 11 clearly shows that the output HTF temperature can be maintained above the red dashed line during the entire 6 hours of discharge by using the trial storage tank volume for PCM-2. Coincidentally, there is no need to go to Step 2 by enlarging the tank volume or extending the charging time. Since the volume of trial storage tank already satisfies the cutoff temperature at the end of $6 \mathrm{~h}$ discharge, further investigation is to see the possibility of reducing the trial storage tank volume. After $17 \%$ of reduction of the trial storage tank volume, the storage tank height for PCM-2 is $42.5 \mathrm{~m}$, which still can meet the target of discharged fluid temperature being above $360{ }^{\circ} \mathrm{C}$ during 6 hours. Correspondingly, the storage tank volume is $3337.9 \mathrm{~m}^{3}$, with a radius of $5 \mathrm{~m}$. The energy storage efficiency is calculated based on Eq. (20), which gives a value of $72.95 \%$. This example offers a special case for LHSS that the trial storage tank volume can satisfy the requirement that the discharged fluid being above the cutoff temperature. The large latent heat of PCM-2 contributes to this phenomenon.

The above two examples demonstrated the procedures starting from finding a trial storage tank volume and followed by trial-and-error search of the final result to satisfy the required temperature for the discharged fluid in a required period of time. As the cutoff temperature is less than the highest temperature of fluid in the storage tank, 
the final result of tank volume can be larger or smaller than the initial trial tank volume influenced by the magnitude of latent heat.

From the study, two kinds of PCMs have been examined, and the storage tank volumes have been obtained through modeling computation by applying the general volume sizing strategy. The two PCMs demonstrated differences of systematic performance, which offers choices for engineers to select.

\subsection{Comparison of storage tank volume with sensible heat storage system}

It is expected that LHSS can offer a significant reduction of storage tank volume compared to the sensible heat storage system (SHSS), therefore a CSP plant using PCM is a promising technology for large scale application of solar energy. In this section, one example will be briefly introduced to illustrate the advantage of a LHSS which may have a significantly reduced storage tank volume compared to a SHSS.

If granite rocks, as used and studied in Reference [35], are adopted as the storage material for the same CSP system introduced in this paper, the same method and procedures utilized in the present paper can be followed to find a storage tank volume by simply replacing the thermo-properties of PCM with that of granite rocks. Therminol VP-1 is still used as HTF. The modified length characteristic $z_{C}^{*}$ for such sensible heat storage system is $0.38 \mathrm{~m}$. Following the same method introduced in this paper to calculate the trial storage tank volume for SHSS, the obtained result of $\tilde{H}$ is 198.1 at a given tank radius of $5 \mathrm{~m}$. Correspondingly, the overall dimensional height of trial storage tank is $75.3 \mathrm{~m}$, and the trial tank volume is $5914.1 \mathrm{~m}^{3}$. Using the trial storage tank volume, it is found that the output HTF temperature at the end of 6 hours of discharge is slightly lower than the cutoff temperature. With a $4.5 \%$ increase of the volume from the trial storage tank volume, the storage tank height of multiple tanks for SHSS was found to be $80.1 \mathrm{~m}$ that can satisfy the need. Similarly, the energy storage efficiency is calculated based on Eq. (20), which gives a value of $97.3 \%$. The storage tank height for SHSS and LHSS are listed in Table 4 for comparison.

Table 4 Comparison of actual storage tank height between SHSS and LHSS with a fixed tank radius of $5 \mathrm{~m}$

\begin{tabular}{c|l|c|c}
\hline Storage system & \multicolumn{1}{|c|}{ Storage material } & Actual storage tank height & Energy storage efficiency \\
\hline \multirow{2}{*}{ SHSS } & Granite Rocks & $80.1 \mathrm{~m}$ & $97.3 \%$ \\
\hline \multirow{3}{*}{ LHSS } & PCM-1 (KOH) with 8h charge & $46.9 \mathrm{~m}$ & $88.19 \%$ \\
\cline { 2 - 4 } & PCM-1 (KOH) with 6h charge & $50.4 \mathrm{~m}$ & $87.61 \%$ \\
\cline { 2 - 4 } & PCM-2 (58\% LiCl, $42 \% \mathrm{KCl})$ & $42.5 \mathrm{~m}$ & $72.95 \%$ \\
\hline
\end{tabular}

The important point to observe from Table 4 is that the storage tank volume has been reduced for at least $35 \%$, and at most of $47 \%$ by adopting PCM compared to granite rocks. This is a significant reduction of the volume of storage tank, which may reduce the cost significantly. The latent heat of PCM is the major contributor to this phenomenon. One can easily observe from Figs. 8, 9, 10 and 11 that the HTF temperature at the exit can be maintained at near the melting point of PCM for a very long time during a discharge process. With respect to the definition of energy storage efficiency by Eq. (20), it is a ratio of energy discharged from a storage tank versus that 
from an ideal thermocline tank. Therefore, the energy storage efficiency only provides the comparison of energy discharge process, which reflects the energy availability for customer. Obviously, high storage efficiency is always preferable, because higher storage efficiency means more energy being extracted from the storage system, and more importantly, meets the demand that the temperature is above a cutoff temperature. From Table 4, SHSS can offer higher energy storage efficiency, but also with larger tank volume, which may have significant higher cost. Although, a LHSS has relatively low energy storage efficiency, the storage tank volume can be reduced significantly, and importantly the discharged fluid can still have temperatures above the cutoff temperature. Factors, such as cyclic exergetic efficiency, have not been considered in this study, which will be discussed in a parametric study in the near future.

As seen from Table 4, the storage tank heights in this study are all very large considering a tank diameter of 10 $\mathrm{m}$, which needs to include multiple tanks with serial connection, or otherwise different tank diameter is needed for new design analysis. The tank radius was randomly picked up, which may cause the other parameters being away from the reality. Nevertheless, it is important to note that the main focus of this paper is to demonstrate a general volume sizing strategy. With the modeling and strategy, it is very convenient to make changes for design and optimization of storage tank dimensions.

\subsection{Cost analysis of thermocline storage systems}

Pacheco et al. [51] presented probably the first cost analysis of a packed bed thermocline system. However, their cost analysis considered few system components and was for a low temperature thermal storage system. EPRI [52] reported a much more thorough and detailed cost analysis for a packed bed thermocline system and a two-tank TES system, considering both direct and indirect contact configurations. In this section, a simply estimated cost analysis for SHSS and LHSS are provided based on the storage tank heights listed in Table 4. The media cost for four different systems are computed and reported in Table 5, and it is easy to observe that LHSS with PCM-2 has the lowest media cost, while SHSS with granite rocks holds the highest cost.

Table 5 TES media cost for three different materials

\begin{tabular}{|c|c|c|c|c|}
\hline \multirow[t]{3}{*}{ Media } & \multicolumn{4}{|c|}{ Thermocline storage materials } \\
\hline & SHSS & LHSS & LHSS & LHSS \\
\hline & Granite rocks & PCM-1, 8h charge & PCM-1, 6h charge & PCM-2, 6 h charge \\
\hline HTF inventory $\left(\mathrm{m}^{3}\right)$ & 1887.3 & 1105 & 1187.5 & 1001.4 \\
\hline HTF unit cost $\left(\$ / \mathrm{m}^{3}\right)$ & $\$ 20,000$ & $\$ 20,000$ & $\$ 20,000$ & $\$ 20,000$ \\
\hline HTF cost & $\$ 37,746,000$ & $\$ 22,100,000$ & $\$ 23,750,000$ & $\$ 20,028,000$ \\
\hline Solid media inventory $\left(\mathrm{m}^{3}\right)$ & 4403.7 & 2578.5 & 2770.9 & 2336.5 \\
\hline Solid media unit cost $\left(\$ / \mathrm{m}^{3}\right)$ & $\$ 35$ & $\$ 204.4$ & $\$ 204.4$ & $\$ 313$ \\
\hline Solid media cost & $\$ 154,129$ & $\$ 527,045$ & $\$ 566,372$ & $\$ 731,324$ \\
\hline Total media cost $(\$)$ & $\$ 151,600,516$ & $\$ 90,508,180$ & $\$ 97,265,488$ & $\$ 83,037,296$ \\
\hline
\end{tabular}

A parabolic trough CSP plant with $60 \mathrm{MW}$ electrical power output at the thermal efficiency of $35 \%$ is chosen 
for study in this work. According to several different distributors introduced by Strasser and Selvam [53] and using the media costs reported in Table 5, the capacity cost for each system was estimated and given in Table 6.

Table 6 Cost analysis of SHSS and LHSS

\begin{tabular}{|c|c|c|c|c|}
\hline \multirow[t]{3}{*}{ Cost contributor } & \multicolumn{4}{|c|}{ Thermocline storage system (60 MWe, $35 \%$ thermal efficiency) } \\
\hline & SHSS & LHSS & LHSS & LHSS \\
\hline & Granite rocks, $6 \mathrm{~h}$ charge & PCM-1, 8 h charge & PCM-1, 6 h charge & PCM-2, 6 h charge \\
\hline Energy storage media & $\$ 151,600,516$ & $\$ 90,508,180$ & $\$ 97,265,488$ & $\$ 83,037,296$ \\
\hline Storage tank & $\$ 8,000,00$ & $\$ 4,000,00$ & $\$ 5,000,00$ & $\$ 3,000,00$ \\
\hline Foundation & $\$ 3,000,000$ & $\$ 3,000,000$ & $\$ 3,000,000$ & $\$ 3,000,000$ \\
\hline Platform and steel & $\$ 2,898,600$ & $\$ 1,449,300$ & $\$ 1,449,300$ & $\$ 1,449,300$ \\
\hline Insulation & $\$ 2,062,800$ & $\$ 1,062,800$ & $\$ 1,062,800$ & $\$ 1,062,800$ \\
\hline Pumps and PCE & $\$ 6,673,660$ & $\$ 6,673,660$ & $\$ 6,673,660$ & $\$ 6,673,660$ \\
\hline Piping and valves & $\$ 2,177,830$ & $\$ 2,177,830$ & $\$ 2,177,830$ & $\$ 2,177,830$ \\
\hline Electrical & $\$ 550,742$ & $\$ 550,742$ & $\$ 550,742$ & $\$ 550,742$ \\
\hline Instrument/controls & $\$ 322,118$ & $\$ 322,118$ & $\$ 322,118$ & $\$ 322,118$ \\
\hline Construction costs & $\$ 11,695,260$ & $\$ 4,847,630$ & $\$ 5,847,630$ & $\$ 3,847,630$ \\
\hline Constr. management & $\$ 1,500,000$ & $\$ 1,500,000$ & $\$ 1,500,000$ & $\$ 1,500,000$ \\
\hline Installed cost & $\$ 182,481,526$ & $\$ 112,092,260$ & $\$ 119,849,568$ & $\$ 103,621,376$ \\
\hline Capacity cost $(\$ / \mathrm{kWh})$ & $\$ 177$ & $\$ 109$ & $\$ 115$ & $\$ 101$ \\
\hline
\end{tabular}

It can be seen from Table 6 that most of the components for the four different storage systems are the same; while the primary cost difference is on the energy storage media. The remaining costs, construction, and management are also assumed the same. Dividing the 'installed cost' of each system by the energy storage capacity expressed in kWh yields the storage capacity cost of each system. As a consequence, it is seen that LHSS of PCM-2 with $6 \mathrm{~h}$ charge has the lowest capacity cost of $\$ 101 / \mathrm{kWh}$, which is about $43 \%$ less than that of SHSS using granite rock with $6 \mathrm{~h}$ charge. While the capacity costs of LHSS of PCM-1 with $8 \mathrm{~h}$ charge and LHSS of PCM-1 with $6 \mathrm{~h}$ charge are at the same level of $\$ 109 / \mathrm{kWh}$. Comparing the thermocline capacity costs, it is found that LHSS has at least $35 \%$, at most $43 \%$ reduction of capacity cost than SHSS.

It is important to note that the capacity costs in Table 6 are much higher than the capacity costs listed in Ref. [53]. This is because the cost of HTF using Therminol VP-1 is much higher than that of Solar Salts. Also, the tank radius and structural design in this study were chosen with randomness, as the main focus of this paper is to show a general volume sizing procedure and methodology. Therefore, there is no sufficient evidence yet to believe that the thermocline storage systems in this study cannot provide any benefit compared to the system designs in Ref. [53].

\section{Concluding Remarks}

This paper proposed a general volume sizing strategy for LHSSs based on the analysis of energy charge/discharge using an enthalpy-based 1D transient model, which was previously developed in Ref. [28]. The 
computations for tank sizing start with finding a basic tank volume (trial volume) and followed by examining the discharged HTF temperatures in steady cyclic operations to satisfy the requirement of above a cutoff temperature in the desired period of heat discharge. Increase of tank volume (on the base of the trial volume) and increase of charging time can be combined to eventually meet the goal of required energy discharge.

The strategy was explicitly demonstrated through design examples of 6 hours' energy discharge for a $60 \mathrm{MWe}$ solar thermal power plant with $35 \%$ thermal efficiency. In the design examples, two different kinds of PCM were considered, and the general sizing strategy was applied to find the storage tank volume for each PCM to satisfy the requirement that the temperature of discharged fluid in 6 hours is above a cutoff temperature. The radius of the storage tanks in the examples were chosen as $5 \mathrm{~m}$. It was found for the LHSS using PCM-1 that 8 hours heat charge is needed to provide 6 hours of required energy discharge using multiple storage tanks with a total height of $46.9 \mathrm{~m}$, or otherwise, 6 hours heat charge to multiple storage tanks in a total height of $50.4 \mathrm{~m}$ can provide 6 hours of required energy discharge. For the LHSS using PCM-2 6 hours of heat charge to multiple tanks with a total height of $42.5 \mathrm{~m}$ will be able to satisfy the need of discharged fluid temperatures being above the cutoff point. Finally an example of SHSS using granite rocks as storage material was compared with LHSS. A significant reduction of storage tank volume by $47 \%$ has been discovered.

\section{NOMENCLATURE}

\begin{tabular}{|cccc|}
\hline$H$ & Overall height of storage tank $(\mathrm{m})$ & $t$ & Time (s) \\
$R$ & Radius of storage tank (m) & $z$ & Axial tank location from reference (m) \\
$r$ & Radius of encapsules (m) & $S t f$ & Stefan number \\
$d_{r}$ & Diameter of encapsules $(\mathrm{m})$ & $H_{C R}$ & Dimensionless heat capacity ratio \\
$\varepsilon$ & Equivalent void fraction & $\tau_{r}$ & Dimensionless time scale \\
$V$ & Volume $\left(\mathrm{m}^{3}\right)$ & $\theta$ & Dimensionless temperature \\
$S_{r}$ & Surface area per length scale $(\mathrm{m})$ & $\eta_{r}$ & Dimensionless enthalpy \\
$f_{s}$ & Surface shape factor & $\eta$ & Energy storage efficiency \\
$\rho$ & Density $\left(\mathrm{kg} / \mathrm{m}^{3}\right)$ & $\Pi_{d}$ & Dimensionless required time of discharge \\
$C$ & Specific heat capacity $(\mathrm{J} / \mathrm{kg} \mathrm{K})$ & $P_{e l e}$ & Total electrical power output (W) \\
$\dot{m}$ & Mass flow rate $(\mathrm{kg} / \mathrm{s})$ & $N_{c y c l e}$ & Number of charge/discharge cycles \\
$h$ & Intrinsic heat transfer coefficient $\left(\mathrm{W} / \mathrm{m}^{2} \mathrm{~K}\right)$ & & \\
$h_{e f f}$ & Effective heat transfer coefficient $\left(\mathrm{W} / \mathrm{m}^{2} \mathrm{~K}\right)$ & Subscripts & \\
$T$ & Temperature $\left({ }^{\circ} \mathrm{C}\right)$ & $f$ & Refer to HTF \\
$\bar{h}$ & Enthalpy $(\mathrm{J} / \mathrm{kg})$ & $r$ & \\
\hline
\end{tabular}




\begin{tabular}{|cccc|}
\hline$U$ & Axial Velocity of HTF $(\mathrm{m} / \mathrm{s})$ & $r_{-}$melt & Refers to a filler melting point value \\
$\operatorname{Re}$ & Reynolds number & $r_{-} s$ & Refers to the filler in a solid phase state \\
$v$ & Kinematic viscosity $\left(\mathrm{m}^{2} / \mathrm{s}\right)$ & $r_{-} l$ & Refers to the filler in a liquid phase state \\
$\operatorname{Pr}$ & Prandtl number & $r_{-} r e f$ & Refers to a filler reference value \\
$L$ & Latent heat of fusion $(\mathrm{J} / \mathrm{kg})$ & $H$ & Refers to the highest value of a variable \\
$k$ & Thermal conductivity $(\mathrm{W} / \mathrm{m} \mathrm{K})$ & $L$ & Refers to the lowest value of a variable \\
\hline
\end{tabular}

\section{ACKNOWLEDGMENT}

The authors are grateful for the support from the U.S. Department of Energy and National Renewable Energy Laboratory under DOE Award: DE-FC36-08GO18155. Thanks are also due to Dr. Dick Solie for his valuable suggestions on the structure and organizing of this paper.

\section{REFERENCES}

[1] Müller-Steinhagen, H., Trieb, F., 2004. Concentrating solar power: A review of the technology. Ingenia Inform QR Academic Engineering 18, 43-50.

[2] Py, X., Azoumah, Y., Olives, R., 2013. Concentrated solar power: Current technologies, major innovative issues and applicability to West African countries. Renewable and Sustainable Energy Reviews 18, 306-315.

[3] Liu, M., Saman, W., Bruno, F., 2012. Review on storage materials and thermal performance enhancement techniques for high temperature phase change thermal storage systems. Renewable and Sustainable Energy Reviews, 16(4), 2118-2132.

[4] Nallusamy, N., Sampath, S., 2007. Experimental investigation on a combined sensible and latent heat storage system integrated with constant/varying (solar) heat sources. Renewable Energy, 32:1206-27.

[5] Verma, P., Singal, S. K., 2008. Review of mathematical modeling on latent heat thermal energy storage systems using phase-change material. Renewable and Sustainable Energy Reviews 12(4), 999-1031.

[6] Agyenim, F., Hewitt, N., Eames, P., Smyth, M., 2010. A review of materials, heat transfer and phase change problem formulation for latent heat thermal energy storage systems (LHTESS). Renewable and Sustainable Energy Reviews, 14(2), 615-628.

[7] Regin, A. F., Solanki, S. C., Saini, J. S., 2008. Heat transfer characteristics of thermal energy storage system using PCM capsules: a review. Renewable and Sustainable Energy Reviews, 12(9), 2438-2458.

[8] Nithyanandam, K., Pitchumani, R., Mathur, A. Analysis of a latent thermocline energy storage system for concentrating solar power plants. Proceedings of the ASME 2012 6th International Conference on Energy Sustainability, ESFuel Cell 2012, July, 2012, San Diego, CA, USA.

[9] Zhang, Y., Zhou, G., Lin, K., Zhang, Q., Di, H., 2007. Application of latent heat thermal energy storage in buildings: state-of-the-art and outlook. Building and Environment, 42(6), 2197-2209.

[10] Khudhair, A. M., Farid, M. M., 2004. A review on energy conservation in building applications with thermal storage by latent heat using phase change materials. Energy conversion and management, 45(2), 263-275. 
[11] Zalba, B., Marín, J. M., Cabeza, L. F., Mehling, H., 2003. Review on thermal energy storage with phase change: materials, heat transfer analysis and applications. Applied thermal engineering, 23(3), 251-283.

[12] Bejan, Adrian. Entropy generation minimization: the method of thermodynamic optimization of finite-size systems and finite-time processes. CRC press, 1996.

[13] Pacheco, J. E., Showalter, S. K., Kolb, W. J., 2002. Development of a molten-salt thermocline thermal storage system for parabolic trough plants. Journal of Solar Energy Engineering, 124(2), 153-159.

[14] Van Lew, J., Li P.W., Chan C.L., Karaki, W., Stephens, J., Transient Heat Delivery and Storage Process in a Thermocline Heat Storage System. Proceedings of the ASME 2009 International Mechanical Congress and Exposition, IMECE 2009, November, 2009, Lake Buena Vista, Florida, USA.

[15] Li, P., Xu, B., Han, J., Yang, Y., 2014. Verification of a model of thermal storage incorporated with an extended lumped capacitance method for various solid-fluid structural combinations. Solar Energy, 105, 71-81.

[16] Li, P.W., Van Lew, J., Karaki, W., Chan, C.L., Stephens, J., Wang, Q., 2011. Generalized charts of energy storage effectiveness for thermocline heat storage tank design and calibration. Solar Energy, 85.9, 2130-43.

[17] Li, P.W., Van Lew, J., Chan, C.L., Karaki, W., Stephens, J., O’Brien, J. E., 2012. Similarity and generalized analysis of efficiencies of thermal energy storage systems. Renewable Energy, 39.1, 388-402.

[18] Wu, M., Li, M., Xu, C., He, Y., Tao, W., 2014. The impact of concrete structure on the thermal performance of the dual-media thermocline thermal storage tank using concrete as the solid medium. Applied Energy, 113, 13631371.

[19] Prasad, L., Muthukumar, P., 2013. Design and optimization of lab-scale sensible heat storage prototype for solar thermal power plant application. Solar Energy, 97, 217-229.

[20] Xu, C., Wang, Z., He, Y., Li, X., Bai, F., 2012. Sensitivity analysis of the numerical study on the thermal performance of a packed-bed molten salt thermocline thermal storage system. Applied Energy, 92, 65-75.

[21] Yang, Z., Garimella, S. V., 2013. Cyclic operation of molten-salt thermal energy storage in thermoclines for solar power plants. Applied Energy, 103, 256-265.

[22] Felix Regin, A., Solanki, S.C., 2009. An Analysis of a Packed Bed Latent Heat Thermal Energy Storage System using PCM capsules: Numerical Investigation. Renewable Energy 34, 1765-1773.

[23] Wu, S., Fang, G., 2011. Dynamic Discharging Characteristics Simulation on Solar Heat Storage System with Spherical Capsules using Paraffin as Heat Storage Material. Renewable Energy, 36, 1190-95.

[24] Nithyanandam, K., Pitchumani, R., Mathur, A. Numerical analysis of latent heat thermal energy storage system with embedded thermosyphones. Proceedings of the ASME 2012 6th International Conference on Energy Sustainability. July, 2012, San Diego, CA, USA.

[25] Nithyanandam, K., Pitchumani, R. 2013. Computational studies on a latent thermal energy storage system with integral heat pipes for concentrating solar power. Applied Energy, 103, 400-415.

[26] Archibold, A. R., Rahman, M. M., Goswami, D. Y., Stefanakos, E. L. Parametric Investigation of the Melting and Solidification Process in an Encapsulated Spherical Container. Proceedings of the ASME 2012 6th International Conference on Energy Sustainability. July, 2012, San Diego, CA, USA. 
[27] Vyshak, N. R., Jilani, G, 2007. Numerical analysis of latent heat thermal energy storage system. Energy conversion and management, 48.7, 2161-2168.

[28] Nithyanandam, K., Pitchumani, R., Mathur, A., 2014. Analysis of a latent thermocline storage system with encapsulated phase change materials for concentrating solar power. Applied Energy, 113, 1446-1460.

[29] Tumilowicz, E., Chan, C.L., Xu, B., Li, P.W., An enthalpy formulation for thermocline with encapsulated PCM thermal storage and benchmark solution using the method of characteristic. Proceedings of the ASME 2013 Summer Heat Transfer Conference, July, 2013, Minneapolis, MN, USA.

[30] Tumilowicz, E., Chan, C.L., Li, P.W., Xu, B., 2014. An enthalpy formulation for thermocline with encapsulated PCM thermal storage and benchmark solution using the method of characteristic. International Journal of Heat and Mass Transfer, 79, 362-377.

[31] Van Lew, J., Li, P.W., Chan, C.L., Karaki, W., Stephens, J., 2011. Analysis of heat storage and delivery of a thermocline tank having solid filler material. Journal of Solar Energy Engineering 133(2), 021003.

[32] Xu, B., Li, P.W., Chan, C.L., 2012. Extending the validity of lumped capacitance method for large Biot number in thermal storage application. Solar Energy 86(6), 1709-1724.

[33] Schumann, T. E., 1929. Heat transfer: a liquid flowing through a porous prism. Journal of the Franklin Institute, 208(3), 405-416.

[34] SunShot, Energy Efficiency and Renewable Energy, U.S. Department of Energy, 2012. SunShot Vision Study:

February 2012. NREL Report No. BK5200-47927; DOE/ GO- 102012-3037.

[35] Xu, B., Li, P.-W., Chan, C.-L. Fluid charge/discharge strategies of dual-media storage system in starting up process of daily cycle operation for a CSP power plant. Proceedings of the ASME 2014 8th International Conference on Energy Sustainability. June, 2014, Boston, MA, USA.

[36] Li, P.-W., Van Lew, J., Karaki, W., Chan, C.-L., Stephens, J., O’Brien, J.E., Transient heat transfer and energy transport in packed bed thermal storage systems. In book "Developments in Heat Transfer", edited by Marco Aurélio dos Santos Bernardes, ISBN 978-953-307-569-3, September 15. 2011.

[37] Incropera, F. P., DeWitt, D. P. Introduction to Heat Transfer, Fourth Ed. John Wiley and Sons, Inc., 2002.

[38] Nellis, G., Klein, S., Heat Transfer, Cambridge University Press, 2009.

[39] Valmiki, M. M., Stephens, J., Karaki, W., Li, P.W., Van Lew, J., Chan, C.L., 2012. Experimental Investigation of Thermal Storage Processes in a Thermocline Tank. J. Sol. Energy Eng. 134(4), 041003.

[40] Yang, Z., Garimella, S. V., 2010. Thermal analysis of solar thermal energy storage in a molten-salt thermocline. Solar energy, 84(6), 974-985.

[41] Bayón, R., Rojas, E., 2013. Simulation of thermocline storage for solar thermal power plants: From dimensionless results to prototypes and real-size tanks. International Journal of Heat and Mass Transfer, 60, 713721.

[42] Nallusamy, N., Sampath S., Velraj, R., 2007. Experimental investigation on a combined sensible and latent heat storage system integrated with constant/varying (solar) heat sources. Renewable Energy, 32, 1206-1227.

[43] Modi, A., Pérez-Segarra, C. D., 2014. Thermocline thermal storage systems for concentrated solar power plants: One-dimensional numerical model and comparative analysis. Solar Energy, 100, 84-93. 
[44] Bejan, Adrian. Advanced Engineering Thermodynamics. Second Edition. John Wiley \& Sons, Inc., 1997.

Entropy generation minimization: the method of thermodynamic optimization of finite-size systems and finite-time processes. CRC press, 1996.

[45] Xu, B., Li, P.-W., Chan, C.-L. Volume Sizing for Thermal Storage with Phase Change Material for Concentrated Solar Power Plant. Proceedings of the ASME 2014 8th International Conference on Energy Sustainability. June, 2014, Boston, MA, USA.

[46] Biencinto, M., Bayón, R., Rojas, E., González, L., 2014. Simulation and assessment of operation strategies for solar thermal power plants with a thermocline storage tank. Solar Energy, 103, 456-472.

[47] Conway, J.H. Sloane, N.J.H., 1998. Sphere Packings, Lattices and Groups, (3rd Edition).ISBN 0-387-98585-9.

[48] Therminol VP-1 heat transfer fluid by Solutia, 1999, Technical Bulletin 7239115B, Solutia, Inc., 1999.

[49] Zalba, B., Marín, J. M., Cabeza, L. F., Mehling, H., 2003. Review on thermal energy storage with phase change: materials, heat transfer analysis and applications. Applied thermal engineering, 23(3), 251-283.

[50] Kenisarin, M. M., 2010. High-temperature phase change materials for thermal energy storage. Renewable and Sustainable Energy Reviews, 14(3), 955-970.

[51] Pacheco, J.E., Showalter, S.K., Kolb, W.J., 2002. Development of a molten-salt thermocline thermal storage system for parabolic trough plants. J. Sol. Energy. Eng. 124, 153-159.

[52] EPRI, 2010. Solar Thermocline Storage Systems: A Preliminary Design Study.

http://et.epri.com/publicdocuments.html-1019581.

[53] Strasser, M. N., Selvam, R. P., 2014. A cost and performance comparison of packed bed and structured thermocline thermal energy storage systems. Solar Energy, 108, 390-402. 